OPEN ACCESS

Edited by:

Martin Ehrbar,

University of Zurich, Switzerland

Reviewed by:

Mikaël M. Martino,

Monash University, Australia

Silvia Minardi,

Northwestern University,

United States

Uwe Freudenberg,

Leibniz Institute of Polymer Research

(LG), Germany

*Correspondence:

Millicent $O$. Sullivan

msulliva@udel.edu

Kristi L. Kiick

kiick@udel.edu

Specialty section:

This article was submitted to

Nanobiotechnology,

a section of the journal

Frontiers in Bioengineering and

Biotechnology

Received: 05 October 2019

Accepted: 27 January 2020

Published: 18 February 2020

Citation:

Hwang J, Sullivan $\mathrm{MO}$ and

Kiick KL (2020) Targeted Drug Delivery via the Use of ECM-Mimetic

Materials.

Front. Bioeng. Biotechnol. 8:69. doi: 10.3389/fbioe.2020.00069

\section{Targeted Drug Delivery via the Use of ECM-Mimetic Materials}

\author{
Jeongmin Hwang ${ }^{1}$, Millicent O. Sullivan ${ }^{1,2 *}$ and Kristi L. Kiick ${ }^{3 *}$ \\ ${ }^{1}$ Department of Biomedical Engineering, University of Delaware, Newark, DE, United States, ${ }^{2}$ Department of Chemical \\ and Biomolecular Engineering, University of Delaware, Newark, DE, United States, ${ }^{3}$ Department of Materials Science \\ and Engineering, University of Delaware, Newark, DE, United States
}

The use of drug delivery vehicles to improve the efficacy of drugs and to target their action at effective concentrations over desired periods of time has been an active topic of research and clinical investigation for decades. Both synthetic and natural drug delivery materials have facilitated locally controlled as well as targeted drug delivery. Extracellular matrix (ECM) molecules have generated widespread interest as drug delivery materials owing to the various biological functions of ECM. Hydrogels created using ECM molecules can provide not only biochemical and structural support to cells, but also spatial and temporal control over the release of therapeutic agents, including small molecules, biomacromolecules, and cells. In addition, the modification of drug delivery carriers with ECM fragments used as cell-binding ligands has facilitated celltargeted delivery and improved the therapeutic efficiency of drugs through interaction with highly expressed cellular receptors for ECM. The combination of ECM-derived hydrogels and ECM-derived ligand approaches shows synergistic effects, leading to a great promise for the delivery of intracellular drugs, which require specific endocytic pathways for maximal effectiveness. In this review, we provide an overview of cellular receptors that interact with ECM molecules and discuss examples of selected ECM components that have been applied for drug delivery in both local and systemic platforms. Finally, we highlight the potential impacts of utilizing the interaction between ECM components and cellular receptors for intracellular delivery, particularly in tissue regeneration applications.

\section{Keywords: targeted drug delivery, extracellular matrix, hydrogel, ECM ligand, ECM cell receptors}

\section{INTRODUCTION}

Conventional drugs have been critical to the effective management of disease. Despite the benefits of free drugs, 118 drugs approved from 1980 to 2009 in the United States were withdrawn from the market, $22 \%$ of them due to safety reasons including hepatic toxicity, severe cardiovascular effects, gastrointestinal issues, and allergic reactions (Qureshi et al., 2011; Prasad, 2014). In addition, safety concerns and inadequate efficacy (78\%) were the main reasons for the failure of $54 \%$ of the 640 therapeutics that entered phase 3 trials between 1998 and 2008, with follow-up through 2015 (Hwang et al., 2016). The pharmacokinetics of any drug compound, including its efficacy and safety, is critically affected by the route of drug entry (Tibbitt et al., 2016). For example, systemically administrated drugs are exposed to the entire circulatory system, and may access multiple tissues/organs within the body in the absence of direct targeting (Blanco et al., 2015); 
for drugs with intracellular targets, additional challenges are posed by the need to navigate the intracellular landscape. The challenges are compounded for drugs that are highly toxic to healthy cells, such as cytostatic drugs for chemotherapeutics or immunosuppressants, adding an extra set of barriers during pre-clinical and clinical evaluation.

To overcome the pharmacokinetic limitations of free drugs, drug delivery systems (DDS) have been designed based on nanomaterials, polymers, and lipids, which can be attached to drugs or used to encapsulate drugs in order to better localize their delivery or control drug release over extended periods (Langer, 1998; Hu et al., 2016; Kanamala et al., 2016; Liu et al., 2016). Nanometer-scale therapeutics can extravasate from circulation and accumulate in some tissues via passive targeting effects (Allen and Cullis, 2004). Such advances were the basis of the improvements in chemotherapy efficacy using liposomal formulations of doxorubicin (Doxil), which was introduced for the treatment of Kaposi's sarcoma in 1995. In addition, over 340 DDS have been approved by the FDA and employed clinically to date (Table 3 from Zhong et al., 2018), and it is clear that nanomaterial DDS have great potential for the targeted delivery of drugs. However, passive targeting is only useful for targeting very specific organs such as tumors (Torchilin, 2014), and even in those cases, some regions of tumors exhibit variations in microvascular permeability that diminish the efficacy of passive targeting.

Local administration provides a simple strategy to enhance active targeting to specific sites, taking advantage of physical localization (Panyam and Labhasetwar, 2003). Employing DDS for localized therapy can improve drug efficacy by preventing the loss of therapeutic agent from the administration site, which minimizes necessary doses and maximizes potency. In addition, polymeric or liposomal carriers can be tailored to achieve sustained release of drugs at optimal therapeutic concentrations in a particular tissue (Sheikhpour et al., 2017; Cervadoro et al., 2018; Raave et al., 2018). As DDS for localized therapy, hydrophilic polymeric hydrogels (for hydrophilic drugs) or nanoparticles (for encapsulation of hydrophobic drugs) can be directly injected or applied to the tissue of interest to achieve sustained and controlled drug release to a particular site through diffusion (Kohane and Todd, 2008; Tibbitt et al., 2016). The tailoring of hydrogel and nanoparticle composition, structure, and porosity has been possible owing to the enormous range of polymers and crosslinking chemistries developed for these applications.

Hydrogels have been designed to exploit the mechanical and biochemical activities of the native extracellular matrix $(\mathrm{ECM})$ to influence cells through cell-matrix interactions (Kharkar et al., 2013; Cai and Heilshorn, 2014; Caliari and Burdick, 2016; Ooi et al., 2017; Zhang and Khademhosseini, 2017). These cell-matrix interactions are pivotal to enhance cell infiltration into the hydrogel and promote cell responses in hydrogels that are appropriate for tissue regeneration and drug delivery applications. To create hydrogels that support cell-matrix interactions, ECM molecules are often utilized in hydrogel formulations. For example, decellularized ECM (dECM) matrices derived from tissues and organs are composed of native ECM molecules, and dECM therefore mimics the structural properties of the native matrix (Crapo et al., 2011; Saldin et al., 2017). Owing to the preservation of biochemical cues from the native tissue microenvironment, dECM matrices trigger cellular response that have been exploited clinically in tissue engineering and regenerative medicine [Tissue Mend ${ }^{\circledR}$ (Stryker Orthopaedics, United States), AlloDerm ${ }^{\otimes}$ (LifeCell Corp. United States), CutffPatch $^{\mathrm{TM}}$ (Organogenesis, United States)]. In addition, the delivery of growth factors (Seif-Naraghi et al., 2012) and microRNA (Hernandez et al., 2018) using dECM has recently been explored.

Owing to the myriad cellular interactions with ECM-based materials, the surfaces of drug-loaded nanoparticles also have been modified with ECM-based materials to increase the extent of ligand-mediated, site-specific DDS. The incorporation of bio-specific ligands such as proteins, polysaccharides, peptides, aptamers, and small molecules, facilitates interaction with specific receptors that are either over-expressed or expressed only in specific tissues or cells to achieve active targeting. For example, it has been reported that $\alpha_{\mathrm{v}} \beta_{3}$ integrin and CD44 receptors are upregulated in various tumor tissues (Danhier et al., 2010). The RGD sequence derived from multiple ECM proteins to target integrin receptors, and hyaluronic acid to target CD44 receptor on cancerous cells, have been widely employed to transport antitumor agents (Murphy et al., 2008; Danhier et al., 2012; Huang and Huang, 2018; Fu et al., 2019). Furthermore, target receptormediated siRNA delivery has been developed utilizing ligands such as peptides, GalNAc, and aptamers (Nikam and Gore, 2018). Alnylam Pharmaceuticals launched the first RNA interference (RNAi) drug, ONPATTRO ${ }^{\oplus}$, which uses lipid nanoparticles to deliver RNAi intravenously and treat polyneuropathy caused by hereditary ATTR amyloidosis (Garber, 2018). As next-generation alternatives of $\mathrm{ONPATTRO}^{\circledR}$, the GalNac ligand has been employed to target asialoglycoprotein receptor (ASGP-R) on the hepatocytes. ASGP-R has been shown to mediate endocytosis and degradation of wide variety of desialylated glycoproteins and neoglycoproteins which contain GalNAc residues on the their N-linked carbohydrate chains, and it recognizes specific markers of autoimmune hepatitis (Roggenbuck et al., 2012). The GalNAc conjugated RNAi systems for treatment of liver diseases are currently in phase III (Table 1 from Morrison, 2018). Thus, active targeting strategies have great potential to optimize the delivery of intracellularly active drugs such as many small molecules, as well as biomacromolecules including nucleic acids, peptides, or proteins, which require specific endocytic pathways for action.

Here, we focus on recent developments in the use of ECM components for actively targeted DDS. In particular, we briefly review ligand-receptor mediated endocytosis and cellular interactions with various ECM components as targeting strategies, and we consider the advantages afforded by each approach. We then provide examples of the use of key ECM components in DDS, either as hydrogels or as ligands applied for targeted intracellular DDS. 
TABLE 1 | The extracellular matrix components and their cell surface receptors.

\begin{tabular}{|c|c|c|}
\hline & Integrin & Non-integrin receptors \\
\hline Collagen & $\alpha_{1} \beta_{1}, \alpha_{2} \beta_{1}, \alpha_{10} \beta_{1}, \alpha_{11} \beta_{1}$ & $\begin{array}{l}\text { Discoidin domain receptors (DDR1 and DDR2), GPVI (platelets), LAIR (immune } \\
\text { cell), OSCAR (osteoblast), and mannose receptors (Endo180 or UPARAP), } \\
\text { syndecan, CD44 }\end{array}$ \\
\hline Fibronectin & $\alpha_{5} \beta_{1}, \alpha_{3} \beta_{1}, \alpha_{8} \beta_{1}$, and $\alpha_{v} \beta_{3}, \alpha_{4} \beta_{1}, \alpha_{4} \beta_{7}, \alpha_{9} \beta_{1}$, & Syndecan \\
\hline Laminin & $\alpha_{1} \beta_{1}, \alpha_{2} \beta_{1}, \alpha_{3} \beta_{1}, \alpha_{6} \beta_{1}, \alpha_{7} \beta_{1}, \alpha_{10} \beta_{1}, \alpha_{6} \beta_{4}, \alpha_{v} \beta_{8}$ & Syndecan, $\alpha$-dystroglycan CD44 \\
\hline Heparan sulfate & & Syndecan, glypicans \\
\hline Chondroitin sulfate & & CD44, NG2, RPTP- $\sigma$, GPI-brevican \\
\hline Hyaluronic acid & & CD44, RHAMM, Toll-like receptors \\
\hline
\end{tabular}

\section{ECM-CELL INTERACTION MEDIATED DRUG DELIVERY APPLICATIONS}

Researchers have exploited an expanded understanding of the interactions between cells and the ECM, as well as increased knowledge about signaling pathways and molecules relevant to the treatment of disease, in designing new, more cell-specific therapeutics and DDS. Cell surface receptors are attractive pharmacological targets since they transduce signals from the extracellular environment to modulate cell responses. Integrins, a major class of transmembrane receptors whose primary role is to recognize and bind ECM, have been a target of therapeutic development for nearly 30 years in the pharmaceutical industry (Goodman and Picard, 2012; Raab-Westphal et al., 2017). However, despite some promising therapeutic advances, the complex biology of integrins has often confounded drug development. Integrins are involved in canonical processes ranging from embryonic development to mature tissue function through binding to their ligands. Therefore, it is critical to understand the mechanisms by which cell-ECM interactions enable cells to sense and respond to extracellular signals encoded in the matrix.

Each ECM molecule has an affinity to a cell surface receptor or receptors, including integrins (Figure 1); moreover, the specific integrins expressed by a given cell depend both on the cell type as well as on the cell's physiological state. Accordingly, DDS can be modified with ECM molecules to serve as ligands that will facilitate drug targeting. These approaches are described below for various classes of ECM that have been particularly fruitful in targeted delivery.

\section{Types of ECM Molecules \\ Proteins}

Extracellular matrix proteins include fibrous proteins such as collagen and elastin, and glycoproteins such as fibronectin, laminins, vitronectin, thrombospondin, chondronectin, osteonectin, and fibrin. Collagen is a major ECM component that provides mechanical support, regulates cellular behavior, and directs tissue development. Collagen fibrils, which are formed by self-assembly of triple helical collagen molecules, are cross-linked to provide mechanical strength and integrity to the ECM, and collagens strongly influence the tensile strength and elasticity of tissue. In addition, collagens interact with integrins to regulate cell adhesion, proliferation, and migration, and collagens also interact with other ECM components to direct matrix remodeling (Leitinger and Hohenester, 2007). Fibronectin also regulates a wide variety of cellular functions including cell adhesion, migration, growth and proliferation, embryonic morphogenesis, and wound healing (Pankov and Yamada, 2002; Zollinger and Smith, 2017). Fibronectin usually exists as a dimer composed two nearly identical subunits (type I, type II, and type III) linked together through disulfide bond formation at their C-termini. The type III subunit contains about 100 amino acids in two anti-parallel $\beta$-sheets, which are also present in collagens, and the type III subunit also encodes integrin binding (via the RGD motif) and heparin-binding domains. Laminins promote cell adhesion and migration, neurite outgrowth, angiogenesis. Laminins are a major component of basement membrane along with collagen type IV, with a structure that is comprised of heterotrimeric glycoproteins; three subunits, $\alpha, \beta$, and $\gamma$, come together to form at least 19 laminin isoforms (Colognato and Yurchenco, 2000; Yao, 2017). These laminin isoforms are specifically expressed in tissues to promote biological activities, including cell differentiation, cell shape and movement, and managing tissue phenotypes and survival. The isoforms can bind to other laminins, proteoglycans, and other ECM proteins via various integrins receptors. Due to the ability of ECM proteins to influence cell fate via interactions with integrins, the biocompatible and biodegradable ECM proteins are widely used natural materials for biomedical application (Ramshaw et al., 2009; Benton et al., 2014; Hinderer et al., 2016).

\section{Polysaccharides}

Extracellular matrix polysaccharides including heparin sulfate, chondroitin sulfate, dermatan sulfate, keratin sulfate and hyaluronic acid provide largely a structural network, as most ECM polysaccharides are not directly involved in cellular interactions, but indirectly through interaction with other proteins. Heparan sulfate/heparin is a linear polysaccharide of repeating $\mathrm{N}$-acetyl glucosamine (GlcNAc)-D-glucuronic acid (GlcA) disaccharide units (Meneghetti et al., 2015), and is often covalently attached to cell-associated proteins such as the syndecans (SDCs) and glypicans (GPCs) to form heparan sulfate proteoglycans (HSPGs) (Christianson and Belting, 2014). HSPGs such as syndecans and glypicans are able to modulate the cellular uptake of bound ligands; in addition, heparin interacts with various proteins to regulate biological process including growth factor or cytokine signaling, coagulation factor activity, microbe-host interactions, and lipoprotein metabolism 


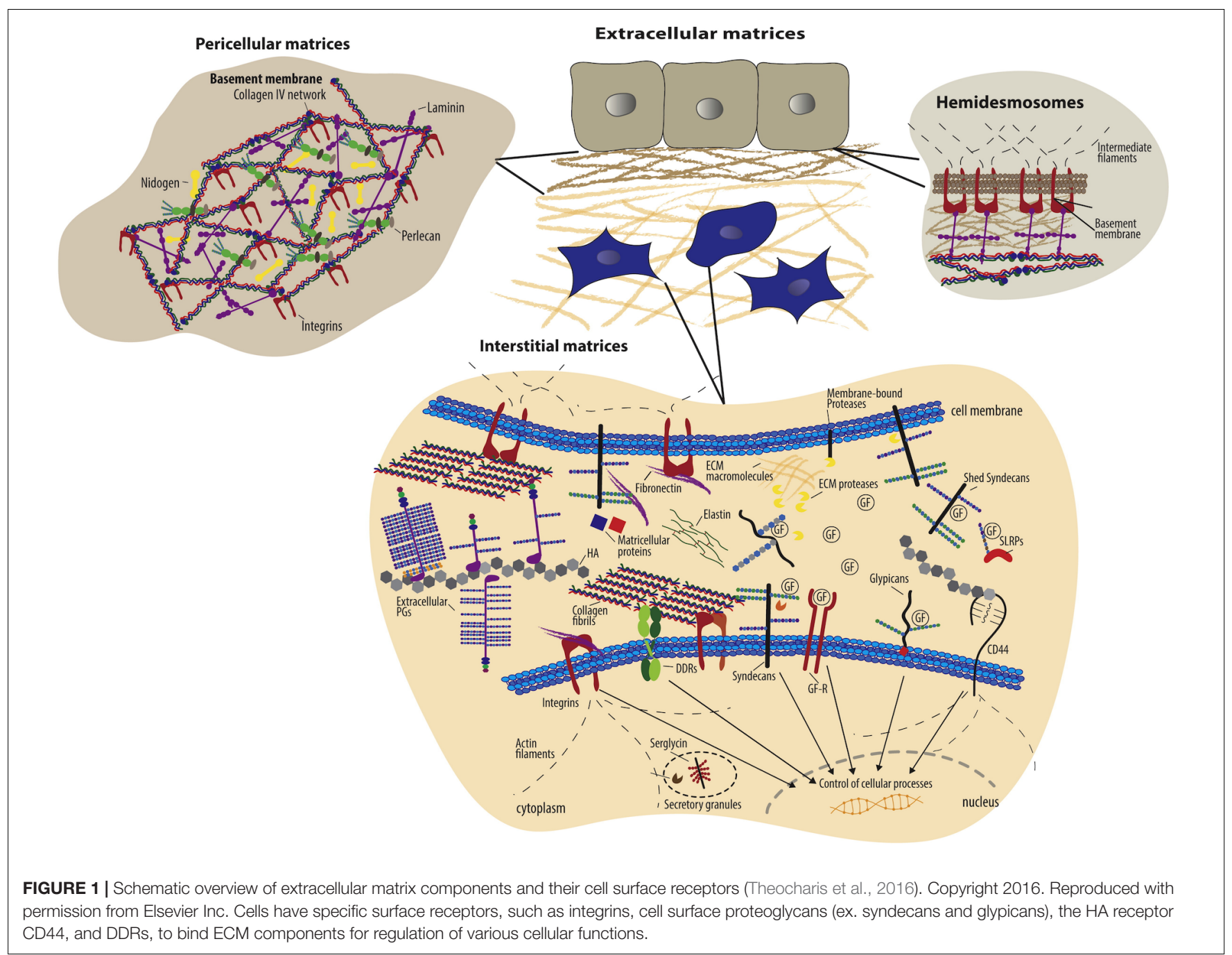

(Belting, 2003). The interaction is highly specific, involving electrostatic forces between the negatively charged heparin and positively charged amino acid residues (e.g., lysine and arginine), and both protects the stability of proteins and increases their affinity for cell receptors (Gospodarowicz and Cheng, 1986). Due to the ability of heparin to interact with proteins, particularly growth factors, heparin has been utilized widely in DDS, with a focus on binding of growth factors (rather than to cell-surface receptors). Heparin-based hydrogels have been widely employed as growth factor carriers for tissue regeneration (Zieris et al., 2010, 2011; Prokoph et al., 2012; Tsurkan et al., 2013; Liang and Kiick, 2014; Freudenberg et al., 2016).

On the other hand, chondroitin sulfate and hyaluronic acid have an affinity to non-integrin cell receptors such as CD44. Chondroitin sulfate is also composed of a sulfated $\beta$ 1,3-linked $\mathrm{N}$-acetyl galactosamine (GalNAc) and $\beta$-1,4-linked D-glucuronic acid (GlcA) disaccharide repeating units. The sulfation pattern defines the different roles of chondroitin sulfate and its selective interaction with molecules mediating such functions as regulation of signal transduction, cell division and morphogenesis, and development of the central nervous system (Zhao et al., 2015). Hyaluronic acid is a non-sulfated polysaccharide composed of disaccharide repeating units of glucuronic acid and $\mathrm{N}$-acetylglucosamine. Hyaluronic acid as a major role in tissue architecture, tissue regeneration, ingrowth of blood vessels, and cellular functions such as motility, adhesion, and proliferation (Jiang et al., 2011) has been utilized in DDS to improve long-acting and target-specific delivery (Tripodo et al., 2015; Highley et al., 2016; Jiao et al., 2016). In particular, due to the highly specific cellular receptor interaction and cellular uptake of hyaluronic acid in kidney, liver, lymphatic vessels, and tumor sites, hyaluronic acid often has been employed as carriers for intracellular drugs such as anti-tumor agents, and nucleic acids (Oh et al., 2010; Dosio et al., 2016; Lallana et al., 2017; Huang and Huang, 2018; Miyazaki et al., 2018).

\section{Interactions of ECM With Cell Receptors}

Extracellular matrix molecules typically interact with cells through both integrin and non-integrin cell surface receptors (Table 1). The integrin receptors primarily bind the ECM proteins to connect with the cytoskeleton and to cooperate with 
growth factor receptors for cell survival, cell cycle progression, and cell migration (Giancotti and Ruoslahti, 1999; Giancotti, 2003; Harburger and Calderwood, 2009). As introduced above, integrins consist of heterodimeric non-covalent association of $\alpha$ and $\beta$ subunits which comprise a specific receptor. In particular, $\alpha$ subunits have a highly specific role in ligand binding for signal transduction (Rosso et al., 2004), with $\alpha_{2} \beta_{1}$, for example, binding to the collagen family, $\alpha_{5} \beta_{1}$ binding to fibronectin, and $\alpha_{\mathrm{v}} \beta_{3}$ binding to fibronectin, vitronectin and fibrinogen as summarized in Table 1 from Alam et al. (2007). Integrin-mediated binding has been leveraged for an enormous range of applications, as multiple integrin receptors, including $\alpha_{\mathrm{v}} \beta_{3}, \alpha_{\mathrm{v}} \beta_{5}, \alpha_{\mathrm{v}} \beta_{6}, \alpha_{\mathrm{v}} \beta_{8}$, $\alpha_{\mathrm{IIb}} \beta_{3}, \alpha_{5} \beta_{1}$, and $\alpha_{8} \beta_{1}$ recognize and bind to the Arg-GlyAsp (RGD) motif which is found in multiple ECM proteins including collagens, fibronectin, laminin, tenascin, vitronectin, and thrombospondin (Ruoslahti and Pierschbacher, 1986; Kim et al., 2011). The RGD sequence as a "minimal" ligand for multiple integrins has been widely used over numerous decades in the development of targeted polymeric and nanoparticle-based therapies. The selectivity of RGD peptide for a specific integrin can be modulated by conformation of the RGD sequence and its flanking residues (Dunehoo et al., 2006). Cyclic peptides, cRGDfK, cRGDyK, and RGDC4 are selective for the integrins $\alpha_{\mathrm{v}} \beta_{3}$ and $\alpha_{\mathrm{v}} \beta_{5}$, which are overexpressed in vasculature of tumor tissue. Likewise, the GFOGER sequence of collagen binds to four different integrin cell receptors $\left(\alpha_{1} \beta_{1}, \alpha_{2} \beta_{1}, \alpha_{10} \beta_{1}\right.$, and $\left.\alpha_{11} \beta_{1}\right)$ (Zeltz et al., 2014); since the $\alpha_{2} \beta_{1}$ integrin receptor is involved in osteogenesis, the GFOGER sequence has been utilized to assist in bone repair (Wojtowicz et al., 2010).

The REDV sequence from fibronectin is a cell adhesion motif to integrin $\alpha_{4} \beta_{1}$, selective for the endothelial cells (Mould et al., 1991; Massia and Hubbell, 1992). Owing to the specificity toward endothelial cells, the REDV sequence has been modified on the system to transport gene to vascular endothelial cells (Wang et al., 2015; Zhou et al., 2016) In addition, the active peptide sequences from laminin are able to interact with integrins, syndecans, $\alpha$-dystroglycan, and $\mathrm{CD} 44$, to perform various biological activities, cell adhesion and neurite outgrowth and proliferation, and angiogenesis, such as those mediated by laminin (Farrukh et al., 2017). The YIGSR sequence and IKVAV sequence from laminin are also cell adhesion domains (Graf et al., 1987; Tashiro et al., 1989), and the RKRLQVQLSIRT (AG73) sequence derived from the mouse laminin $\alpha 1$ chain interacts with syndecans to promote cell adhesion, neurite outgrowth, and angiogenesis (Hoffman et al., 2001). In contrast, DFKLFAVYIKYR-GGC (C16Y), derived from the mouse laminin $\gamma 1$ chain, binds to integrin $\alpha_{\mathrm{v}} \beta_{3}$ and $\alpha_{5} \beta_{1}$ receptors (Hamano et al., 2012). Laminin-derived peptides have been incorporated into the delivery systems of anti-tumor agents to enhance their specificity to highly expressed laminin receptors on cancer cells, including YIGSR for the $32 / 67 \mathrm{kD}$ receptor, IKVAV for the $\alpha_{3} \beta_{1}$ and $\alpha_{6} \beta_{1}$ integrin receptors, AG73 for syndecan-2 receptor and C16Y for the $\alpha_{\mathrm{v}} \beta_{3}$ integrin receptors (Dubey et al., 2010; Negishi et al., 2011; Hamano et al., 2012; Okur et al., 2016; Negishi and Nomizu, 2019).

Short synthetic peptides derived from ECM proteins retain the integrin-binding function, thus are attractive in the design of materials. For example, the Stupp group has developed bioactive peptide amphiphiles (PA) for regenerative medicine applications (Boekhoven and Stupp, 2014; Hendricks et al., 2017; Sato et al., 2018). The RGDS sequence has been attached to PA to induce integrin-mediated adhesion, spreading or migration of fibroblasts, breast cancer cells, and bone marrow mononuclear cells in vitro (Storrie et al., 2007; Webber et al., 2010; Zhou et al., 2019). In addition, the IKVAV sequence has been added to PA to induce differentiation of progenitor cells into neurons (Silva et al., 2004). In addition, these ECM proteins have binding sites for both integrin and growth factors. Once ECM proteins engage integrins for adhesion, the proximity of the cell to the ECM localizes the growth factors to their cell surface receptors to induce and/or amplify the signaling for development or repair. Capitalizing on this biological cooperativity offers an enormous advantage in ECM protein-based systems for delivery of growth factors, particularly, in inflammatory diseases where the growth factors are easily degraded (Park et al., 2017). ECM protein-based DDS are able to protect growth factors while delivering them to their receptor sites to regulate cellular responses.

Non-integrin cell receptors for ECM molecules include CD36, certain laminin-binding proteins, and proteoglycans (Rosso et al., 2004) comprising glycosaminoglycan (GAG) chains such as heparan sulfate, chondroitin sulfate, dermatan sulfate and keratin sulfate (Mythreye and Blobe, 2009). Proteoglycan co-receptors (CD44, glypicans, neuropilins, syndecans, and TRRIII/betaglycan) mediate interactions with ligands, ECM proteins or other cell surface receptors to promote the formation of cell surface receptor-signaling complexes, and also to regulate cell adhesion, migration, morphogenesis, and differentiation. Among the proteoglycan co-receptors, syndecan and CD44 receptors also bind ECM molecules. Syndecan receptors bind collagens, fibronectin, and laminin and growth factors (e.g., fibroblast growth factor) to assemble signaling complexes with other receptors to control cellular differentiation and development (Yoneda and Couchman, 2003), and CD44 receptors bind to type I and IV collagens and hyaluronan to regulate cell adhesion and movement (Cichy and Pure, 2003). These ECM molecules have been exploited in the DDS not only to target cells that highly expressed those receptors in certain pathological conditions, but also to control the regulation of cellular responses.

Collagen directly interacts with four different integrin cell receptors, $\alpha_{1} \beta_{1}, \alpha_{2} \beta_{1}, \alpha_{10} \beta_{1}$, and $\alpha_{11} \beta_{1}$, depending on the type and form of collagen (Zeltz et al., 2014). $\alpha_{2} \beta_{1}$ and $\alpha_{11} \beta_{1}$ integrins primarily interact with the fibrillar collagen type I (e.g., $\alpha_{2} \beta_{1}$ integrin mediates collagen type I binding for phagocytosis in fibroblasts (Rainero, 2016), while $\alpha_{1} \beta_{1}$ and $\alpha_{10} \beta_{1}$ interact with the non-fibrillar collagens IV and VI. Collagen also binds to nonintegrin receptors such as discoidin domain receptors (DDR1 and DDR2), the GPVI receptor on platelets, the LAIR receptor of immune cells, the OSCAR receptor of osteoblasts, and mannose receptors (Endo180 or uPARAP) (An and Brodsky, 2016). Under particular pathological conditions, these collagen receptors are highly expressed. Endo180/uPARAP receptor is overexpressed by malignant cells in sarcomas, glioblastomas, subsets of acute myeloid leukemia (Nielsen et al., 2017). For integrins, expression 
of $\alpha_{1} \beta_{1}$ and $\alpha_{2} \beta_{1}$ was localized to scleral fibroblast focal adhesions and expression of integrin $\alpha_{11} \beta_{1}$ is restricted to tumor stroma or other fibrotic disease (McBrien et al., 2006; Schnittert et al., 2018). Collagen as a ligand to target these pathological conditions thus represents a powerful therapeutic strategy.

Fibronectin binds both integrin receptors and other ECM molecules. Fibronectin type $\mathrm{III}_{10}$ domain which includes the RGD sequence, is the binding sites for integrins, $\alpha_{5} \beta_{1}, \alpha_{3} \beta_{1}$, $\alpha_{8} \beta_{1}$, and $\alpha_{\mathrm{v}} \beta_{3}$ in a broad range of cell types and tissues (Pankov and Yamada, 2002). In particular, $\alpha_{5} \beta_{1}$ integrin is required for internalization of fibronectin through caveolin-1 dependent endocytosis in myofibroblasts (Rainero, 2016). And, $\alpha_{4} \beta_{1}$ and $\alpha_{4} \beta_{7}$ integrins recognize the LDV and REDV motifs in the alternatively spliced $\mathrm{V}$ region, IDAPS in the $\mathrm{III}_{14}$ domain, and KLDAPT in the $\mathrm{III}_{5}$ domain. In addition, $\alpha_{4} \beta_{1}$ and $\alpha_{9} \beta_{1}$ binds the EDGIHEL sequence in the alternatively spliced EDA segment. Fibronectin also contains two heparin-binding domains within its $\mathrm{V}$ domain to interact with heparin and chondroitin sulfate for cell adhesion, and the fibronectin $\mathrm{I}_{6-9}$ and $\mathrm{II}_{1,2}$ domains recognize denatured collagens to clear them from blood and tissue. The expression of the various fibronectin integrin receptors depends on the pathological conditions, providing targets for DDS. The integrins $\alpha_{5} \beta_{1}$ and $\alpha_{\mathrm{v}} \beta_{3}$ are upregulated in angiogenic vessels during angiogenesis (Ruoslahti, 2002); in particular, the integrin $\alpha_{V} \beta_{3}$ is not expressed in healthy adult animal tissue but overexpressed during angiogenesis in tumor tissues, allowing for the targeting of integrin $\alpha_{V} \beta_{3}$ with fibronectin-based, chemotherapeutic DDS.

Moreover, laminin binds various integrins receptors $\left(\alpha_{1} \beta_{1}\right.$, $\alpha_{2} \beta_{1}, \alpha_{3} \beta_{1}, \alpha_{6} \beta_{1}, \alpha_{7} \beta_{1}, \alpha_{10} \beta_{1}, \alpha_{6} \beta_{4}$, and $\alpha_{v} \beta_{8}$ ) (Alam et al., 2007). Laminin-1, 2, 5, 8, 10, 11 isoforms interact with integrins $\alpha_{3} \beta_{1}$ and $\alpha_{6} \beta_{1}$ which regulate embryonic development, epithelial regeneration, and wound healing processes, and which also internalize to endosome as well (Das et al., 2017). Laminin binding cell receptors are highly expressed in various cancer cells types. For example, integrins $\alpha_{3} \beta_{1}$ and $\alpha_{6} \beta_{1}$ are overexpressed in various epithelial cancers. Amongst non-integrin receptors, laminin receptor (LAM 67R) is overexpressed on human prostate cancer cells and syndecan-2 is overexpressed in various cancer cell lines and during angiogenesis (Shukla et al., 2012). Based on expression of laminin receptors in certain pathological condition, laminin or synthetic laminin mimetic peptides as ligand are utilized as ligands to target and deliver therapeutic agents.

Chondroitin sulfate interacts with cell-surface CD44 receptors. CD44 receptors are an attractive target as they are a cancer stem cell marker which is overexpressed about fourto five-fold in metastasis and cancer progression (Goebeler et al., 1996). Owing to the interaction between chondroitin sulfate and CD44 receptor, chondroitin sulfate has been utilized in DDS to target CD44 overexpressing cancer cells and promote receptor-mediated endocytosis. The polysaccharide hyaluronic acid binds toll-like receptors, CD44, and RHAMM on cell membrane. Interactions with toll-like receptors regulate signaling in inflammatory cells and other cell types, and those with CD44 control leukocyte homing and recruitment. In addition, hyaluronic acid interactions with CD44 and RHAMM regulates tumor growth and metastasis. CD44 expression is characteristic in cells under certain pathological conditions such as infarcted myocardium, infiltrating leukocytes, wound myofibroblasts, vascular cells, and many tumor cells.

\section{Receptor-Mediated Endocytosis}

The efficacy, biomedical function, biodistribution, and toxicity of drugs with intracellular targets of action are dictated by their internalization into the cells through interaction with the exterior of the plasma membrane and their endocytic pathway (Sahay et al., 2010; Foroozandeh and Aziz, 2018). Endocytosis occurs via two primary routes - phagocytosis and pinocytosis (Yameen et al., 2014), with phagocytosis characteristic of dendritic cells, neutrophils, monocytes and macrophages (Aderem and Underhill, 1999) and pinocytosis, which occurs via clathrin-mediated endocytosis, caveolae-mediated endocytosis, clathrin/caveolae-independent endocytosis, and micropinocytosis (Sahay et al., 2010; Yameen et al., 2014), possible for all cell types. Micropinocytosis is an actin-driven endocytic process that initiates the activation of receptor tyrosine kinases (e.g., via growth factors) to polymerize actin and form macropinosomes for cell entry. Unlike micropinocytosis, receptor-mediated endocytosis (e.g., clathrin-mediated endocytosis, caveolae-mediated endocytosis, and clathrin/caveolase-independent endocytosis) is regulated by specific interactions between a receptor and an extracellular ligand or particle (Yameen et al., 2014). Physical properties of the extracellular cargo, including particle size, shape, and surface charge, all influence the cellular uptake pathway. In addition to these physical properties, very specific ligand-receptor interactions dictate the receptor-mediated endocytosis pathways of ligand-decorated cargo.

The majority of DDS are internalized into cells through the clathrin-mediated endocytosis pathway using interactions with numerous receptors on cell membrane including transferrin, asialoglycoprotein receptor, epidermal growth factor receptor, chemokine receptors, and cell adhesion receptors (Tsuji et al., 2013; Xu et al., 2013; D'Souza and Devarajan, 2015; Phuc and Taniguchi, 2017; Hu et al., 2018; Nieto Gutierrez and McDonald, 2018). In this process, particular ligands in the extracellular fluid bind to the receptors on the surface of the cell membrane, which is rich in clathrin, to form a ligand-receptor complex (Munsell et al., 2016) that forms a clathrin-coated pit and results in the formation of clathrin-coated vesicles approximately 10 to $200 \mathrm{~nm}$ in diameter for internalization. After internalization, the clathrin coat on the vesicles is expelled and recycled to the plasma membrane and the vesicle fuses with the early endosomes. The cargo within early endosomes will reach lysosomes and eventually be degraded by the acidic $\mathrm{pH}$ and digestive enzyme of the lysosome. Given the relatively large number of binding molecules, clathrin-mediated endocytosis is a primary uptake pathway for most polymeric DDS.

Polymer-mediated nucleic acid delivery systems have been reported with both clathrin-mediated endocytosis and caveolaemediated endocytosis as their uptake pathways, depending on the size, types, and surface charge of their cargos, and cellular microenvironment (2D vs. 3D) (El-Sayed and Harashima, 2013; Truong et al., 2019). However, trafficking of cargo through 
caveolae-mediated endocytosis routes enhances gene expression owing to the low or non-acidifying pathway (Rejman et al., 2005; Reilly et al., 2012). Caveolae-mediated endocytosis occurs via association of the delivery vehicle with cholesterol-rich lipid rafts in the plasma membrane for cellular entry (Sahay et al., 2010). Once cargo molecules bind to the caveolae surface rich in glycosphingolpids including GM-1 and Gb3, the caveolae engulf the cargo to form vesicles approximately $50 \mathrm{~nm}$ in diameter. The detached caveolar vesicles can fuse with early endosomes, but because the caveolar vesicles have neutral $\mathrm{pH}$, they generally avoid fusion with lysosomes thus preventing lyososomal degradation of drug cargo.

Clathrin-and caveolae-independent endocytosis occurs without binding of the cargo to clathrin or caveolae (Yameen et al., 2014); the pathway depends instead on cell-surface molecules such as Arf-6, flotillin, Cdc42, and RhoA, involving different subtypes of internalization routes depending on the specific cell-surface molecule. Once cargo is internalized, it is usually delivered to the early endosome and trafficked though lysosomal pathways.

The ECM is constantly remodeled, via balancing of synthesis, deposition, and degradation to control tissue homeostasis, and during this process ECM molecules themselves are internalized through receptor-mediated endocytic pathways. Degradation of the ECM occurs largely through two pathways; extracellular degradation mediated by matrix metalloproteases (MMPs) and lysosomal degradation after receptor-mediated internalization (Rainero, 2016). The internalization of the most abundant component of ECM, collagen, is controlled by integrin-mediated phagocytic uptake and Endo-180 dependent clathrin mediated pathway. Fibrillar collagen type I binds to $\alpha_{2} \beta_{1}$ integrin receptor, promoting internalization of collagen to early endosomes (Arora et al., 2013). On the other hand, soluble collagen type I, IV and $\mathrm{V}$ fragments bind Endo180 or UPARAP to internalize to endosome via the clathrin-dependent endocytic pathway (Madsen et al., 2011).

Similar to collagens, fibronectin is degraded by lysosomal degradation after endocytosis. Endocytosis of both soluble and matrix fibronectin is mediated by $\alpha_{5} \beta_{1}$ integrin receptor via caveolin-1 dependent uptake (Shi and Sottile, 2008). Fibronectin binding to $\alpha_{2} \beta_{1}$ integrin receptor, ultimately leading to endosomal sorting and transport to the lysosome (Lobert et al., 2010). The internalization of the major component of basement membrane, laminin, is controlled by $\alpha_{3} \beta_{1}$ integrin receptor and dystroglycan for protein turnover. Interestingly, the activation of the $\alpha_{3} \beta_{1}$ integrin receptor by laminin binding results in phagocytosis of other ECM molecules as well (Coopman et al., 1996). The internalization of laminin requires dystroglycan for receptor-mediated and dynamin-dependent pathways, leading to lysosomal degradation (Leonoudakis et al., 2014). Meanwhile, degradation of hyaluronic acid is controlled by multiple events. High molecular weight hyaluronic acid is degraded to smaller fragments by the extracellular hyaluronic acid-digesting enzyme, hyaluronidase 2 (Hyal 2) (Racine and Mummert, 2012). These fragments can be endocytosed by either receptor-mediated endocytosis $\left(10^{4} \mathrm{Da}\right)$ or micropinocytosis $\left(10^{6} \mathrm{Da}\right)$, depending on the molecular weight of the fragment. Hyaluronic acid fragments binding to CD44 and lymphatic vessel endothelial-1 (LYVE-1) receptors promote the endocytosis of hyaluronic acid via the clathrin-mediated pathway. The wide range of different internalization mechanisms for ECM molecules can be exploited in DDS for the selective uptake of intracellularly active drugs.

\section{ECM-TARGETED DELIVERY OF PARTICLE-BASED DDS}

Extracellular matrix molecules have been successfully formulated into particles for drug delivery applications. The chondroitinsulfate modified CD44 receptor is able to bind to triple helical sequence from collagen Type IV (Rezler et al., 2007); Fields and co-workers thus developed CD44-binding, collagen-mimetic peptides $\left[(\mathrm{GPO})_{4} \mathrm{GVKGDKGNPGWPGAP}(\mathrm{GPO})_{4}\right]$ and used them to modify liposomes as a DDS to cancer cells with highly expressed CD44 cell receptor (Table 2). They demonstrated that doxorubicin delivered via this DDS reduced the tumor size up to $60 \%$, compared to untreated control in a CD $44^{+}$ mouse melanoma model (Ndinguri et al., 2012). Moreover, others have taken advantage of another collagen receptors, DDR2, which is highly expressed in fast-growing invasive tumors (Leitinger, 2014). The Brodsky group reported a recombinant collagen protein (VCLCL-DDRT) that binds DDR2 and could thus serve as a potential tumor treatment (An and Brodsky, 2016). They showed the delay of megakaryocyte migration as a result of the competition between the recombinant VCLCLDDRT and animal collagen for binding to DDR2. In addition, our group recently has developed conjugates of the collagenlike peptide $\left[(\mathrm{GPO})_{4} \mathrm{GFOGER}(\mathrm{GPO})_{4} \mathrm{GG}, \mathrm{CLP}\right]$ and elastinlike peptide $\left[(\mathrm{VPGFG})_{6}, \mathrm{ELP}\right]$ to serve as thermoresponsive vesicles as a drug carrier (Figure 2A) (Luo et al., 2017). This CLP-decorated vesicle has both thermally responsive assembly behavior owing to the temperature-responsiveness of the CLP domain's triple helix formation, and a strong affinity to native collagen through collagen triple helix hybridization, and is therefore able to sequester, for at least 21 days, a hydrophobic model compound (fluorescein) in collagen type II films, with subsequent thermally triggered release. The vesicles also show high cytocompatibility with both fibroblasts and chondrocytes and essentially no activation of a macrophage cell line. The ELPCLP conjugates have the potential to deliver intracellularly active drugs through receptor-mediated endocytosis using interactions between the GFOGER sequence on CLP and integrin receptors $\left(\alpha_{1} \beta_{1}, \alpha_{2} \beta_{1}, \alpha_{10} \beta_{1}\right.$, and $\left.\alpha_{11} \beta_{1}\right)$ (Zeltz et al., 2014).

The use of fibronectin-based molecules has also been employed for successful targeting and increased intracellular uptake of local DDS. The Akaike group incorporated fibronectin in a calcium phosphate co-precipitated, non-viral gene delivery system (Chowdhury and Akaike, 2006); the fibronectin coating in calcium phosphate and pDNA precipitate allowed cellsurface integrin receptor binding for internalization into cells and supported 100-fold higher levels of gene expression than without the fibronectin coating. In the past, direct conjugation of the cyclic RGD peptide, RGD4C, on the anticancer agent, doxorubicin, demonstrated better efficacy in suppressing 
TABLE 2 | Extracellular matrix protein-derived peptides as ligands to bind to cell surface receptors in drug delivery systems.

\begin{tabular}{|c|c|c|c|c|}
\hline ECM molecules & Peptides & Cell receptor & Application & References \\
\hline \multirow[t]{3}{*}{ Collagen } & GGYGGGP(GPP) ${ }_{5}$ GFOGER(GPP) ${ }_{5}$ GPC & $\alpha_{2} \beta_{1}$ & Local protein delivery & Shekaran et al., 2014 \\
\hline & $(\mathrm{GPO})_{4}$ GVKGDKGNPGWPGAP(GPO) 4 & Chondroitin sulfate modified CD44 & Anti-cancer drug delivery & Ndinguri et al., 2012 \\
\hline & VCLCL-DDRT (Recombinant protein) & DDRs & Block the activity of cancer cell & An and Brodsky, 2016 \\
\hline \multirow[t]{3}{*}{ ECM proteins } & cRGD4C & $\alpha_{v} \beta_{3}$ and $\alpha_{v} \beta_{5}$ & Anti-cancer drug delivery & Arap et al., 1998 \\
\hline & cRGDfC & $\alpha_{v} \beta_{3}$ and $\alpha_{v} \beta_{5}$ & Anti-cancer drug delivery & Bibby et al., 2005 \\
\hline & cACRGDMFGCA & $\alpha_{v} \beta_{3}$ and $\alpha_{v} \beta_{5}$ & VEGFR2-SiRNA delivery & Schiffelers et al., 2004 \\
\hline \multirow[t]{2}{*}{ Laminin } & RKRLQVQLSIRT & Syndecan & Anti-cancer drug delivery & Negishi and Nomizu, 2019 \\
\hline & DFKLFAVYIKYR-GGC (C16Y) & Integrin $\alpha_{v} \beta_{3}$ & Anti-cancer drug delivery & Hamano et al., 2012 \\
\hline
\end{tabular}

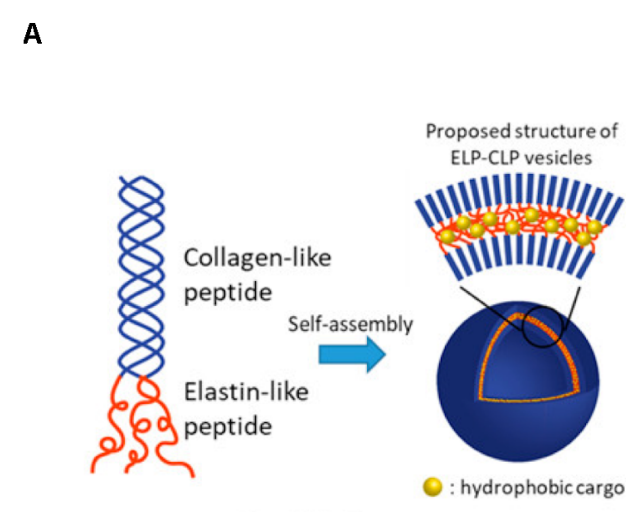

C

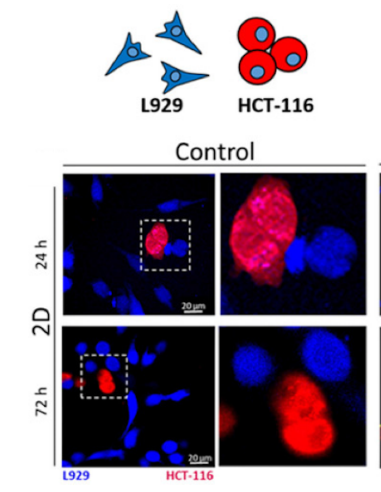

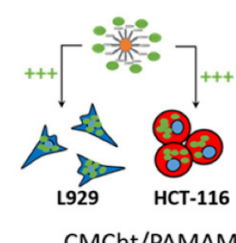

CMCht/PAMAM

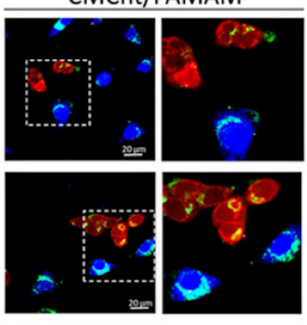

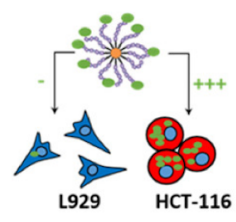

YIGSR-CMCht/PAMAM

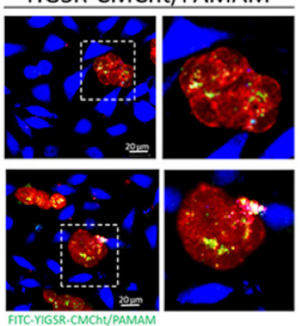

B
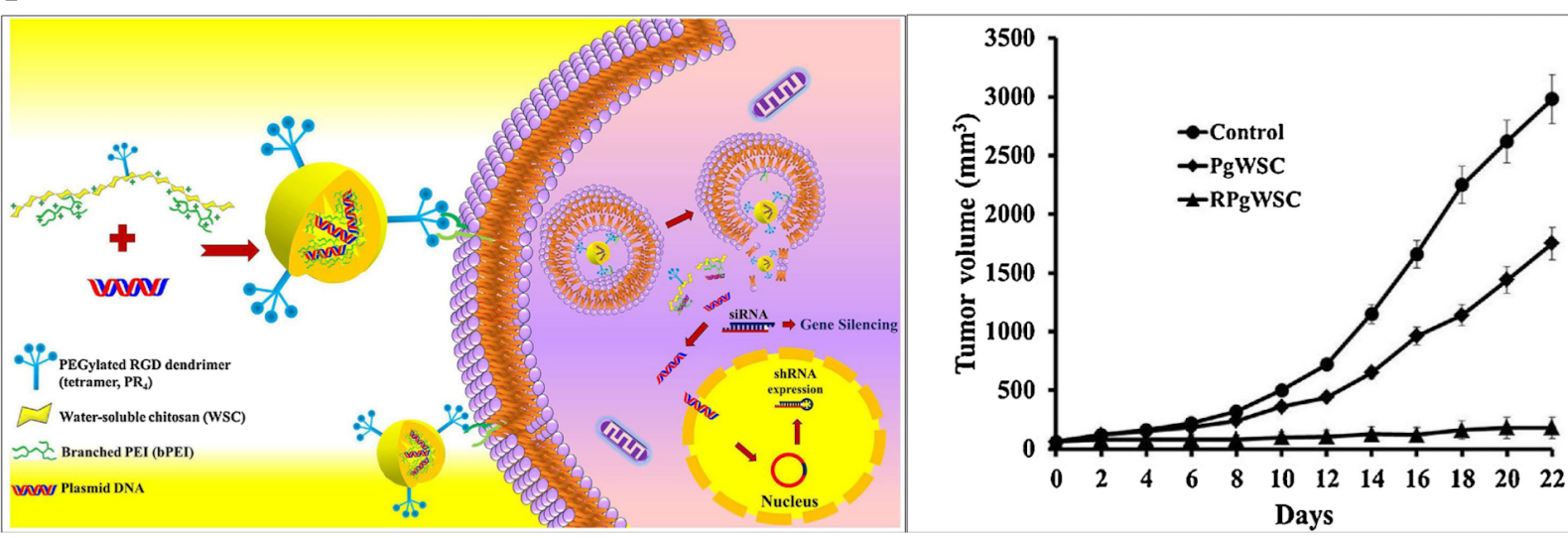

FIGURE 2 | Extracellular matrix-based targeted delivery of particle-based DDS. (A) Schematic of ELP-CLP conjugate-based thermoresponsive nanovesicles (Luo et al., 2017). Copyright 2017. Reproduced with permission from American chemical society. (B) RGD dendrimer peptide modified polyethyleneimine-grafted chitosan for siRNA delivery. In vivo tumor growth of treatment with non-RGD-modified system (PgWSC) and RGD-modified system (RpgWSC), and non-treatment (Y.M. Kim et al., 2017). Copyright 2017. Reproduced with permission from Elsevier Inc. (C) Confocal images of internalization of dendrimer particles (CMCht/PAMAM and YIGSR-CMCht/PAMAM) on HCT-116 cancer cells (red) and L929 fibroblasts (blue) (Carvalho et al., 2019). Copyright Wiley-VCH Verlag GmbH. \& Co. KGaA. Reproduced with permission.

tumor progression than doxorubicin alone, in mouse models bearing human breast carcinoma cells (Arap et al., 1998). The RGD peptide-modified DDS showed improved localization and intracellular uptake into cancer cells. The Jang group investigated the dendrimeric RGD peptides modified on copolymer, which consists of polyethyleneimine and water soluble chitosan (RpgWSC), for an siRNA delivery system to target $\alpha_{v} \beta_{3}$ integrin-overexpressing tumor cells for cancer therapy
(Figure 2B; Kim et al., 2017). The delivery systems allow the cellular uptake of siRNA to PC3 cancer cells through microtubule-dependent micropinocytosis and clathrin-mediated endocytosis. The delivery of siRNA, via the use of their DDS with RGD (RpgWSC), for silencing the mRNA encoding the hBCL2 protein in a PC3 tumor xenograft mouse model, presented greater inhibition of tumor growth through the blocking of BCL2 protein expression, compared to a non-RGD modified delivery system 
(PgWSC) (Figure 2B). These results are a recent illustration of the power of employing RGD in DDS for improving delivery of intracellularly active cancer therapeutics into $\alpha_{v} \beta_{3}$ integrin overexpressing tumor cells.

The active sequence peptides from laminin are able to interact with cell surface receptors, integrins, syndecans, $\alpha$-dystroglycan, and CD44, to perform various biological activities like those mediated by full-length laminin. The laminin-derived RKRLQVQLSIRT (AG73) peptide was modified with PEGylated liposomes to deliver plasmid DNA in human embryonic kidney carcinoma cells, which overexpress syndecan2 (Negishi et al., 2010; Negishi and Nomizu, 2019). On the other hand, cancer cells, including bile duct carcinoma, colorectal carcinoma, cervical cancer, and breast carcinoma, highly express the $67 \mathrm{KDa}$ laminin receptor (67LR), for which the lamininderived YIGSR sequence has high affinity. YIGSR-modified carboxylmethychitosan/poly(amidoamine) (CMCht/PAMAM) dendrimer nanoparticles were developed to drive targeted internalization into colorectal cancer cells (HCT-116 CRC cells) (Carvalho et al., 2019) via this interaction. The YIGSRmodified CMCht/PAMAM nanoparticles were more selectively internalized by HCT-116 colorectal cancer cells than by L929 fibroblasts and non-YIGSR-modified CMCht/PAMAM nanoparticles were non-selectively internalized by both types of cells (Figure 2C). Laminin-based material modification are a promising strategy to improve the specificity of the delivery system on the laminin receptor expressed cells such as tumor.

Heparin is incorporated in DDS to target overexpressed angiogenic growth factors in tumor tissues (Shing et al., 1984). Tae groups demonstrated heparin-coated PLGA nanoparticle to accumulate in the tumor in SCC7 tumor-bearing athymic mice (Chung et al., 2010). In addition, dendronized heparindoxorubicin conjugate-based nanoparticle developed by $\mathrm{Gu}$ group represented the improvement of antitumor efficacy and anti-angiogenic effects in a mouse $4 \mathrm{~T} 1$ breast cancer tumor model, compared to free doxorubicin (She et al., 2013). On the other hand, many studies have investigated the DDS incorporating hyaluronic acid or chondroitin sulfate as a ligand to target CD44-overexpressing cancer cells. Gupta and co-workers formulated polyehtylenimine (PEI) conjugated chondroitin sulfate to form complexes with plasmid DNA (Pathak et al., 2009). Their system, administrated by intravenous injection in Ehrlich ascites tumor (EAT)-bearing mice, accumulated in tumor mass to a significantly greater extent as compared to non-chondroitin sulfate-modified PEI/pDNA complex. The attachment of hyaluronic acid on liposomes loaded with doxorubicin resulted in the selective binding of the DDS on CD44-expressing murine melanoma cells, resulting in a substantial reduction in the $\mathrm{IC}_{50}$ (Eliaz and Szoka, 2001). In addition, Zhang group developed ternary complex based on hyaluronic acid, dexamethasone conjugated polyethyleneimine (PEI) and plasmid DNA to enhance CD44 receptor-mediated endocytosis (Fan et al., 2013). This ternary complex improved cellular uptake and nuclear transport of DNA in melanoma tumor cells, leading to the highest transfection efficiency and suppressed the growth of tumor in mice. Hyaluronic acid has also been utilized to target CD44 receptors overexpressed in macrophages as a strategy for the treatment of inflammatory disease. Pilehvar-Soltanahmadi and co-workers reported hyaluronic acid-conjugated polylactide nanoparticles encapsulated curcumin delivered to macrophage to achieve the modulation of macrophage polarity from the pro-inflammatory M1 phenotype to the anti-inflammatory M2 phenotype (Farajzadeh et al., 2018). The modification of ECM polysaccharides accomplishes the delivery of drugs at the target sites where their receptors are highly expressed.

\section{ECM-BASED HYDROGEL MATRICES FOR DRUG DELIVERY}

Drug transport within a hydrogel can be controlled by manipulating its mesh size and/or its interaction with drugs using chemical strategies (Merino et al., 2015; Li and Mooney, 2016; Sood et al., 2016; Oliva et al., 2017; Dimatteo et al., 2018). Hydrogels comprise crosslinked polymer networks, and drugs smaller than the network mesh size can simply diffuse through the hydrogel, whereas drugs larger than the mesh size are entrapped in the hydrogel and released upon degradation of the network. The polymer backbone and crosslinks can be degraded by either slow hydrolysis of ester bonds or peptide bonds, by the scission of thiol-based crosslinks, or by bioresponsive mechanisms such as enzyme activity (Lutolf et al., 2003; Zustiak and Leach, 2010; Wang, 2018). The degradation of hydrogels in biomedical applications can be tuned based on the local cellular environment by incorporating crosslinks comprising peptides that are degradable by different types of matrix metalloproteinases (Patterson and Hubbell, 2010). Moreover, drug release from the hydrogel can be modulated by incorporating non-covalent or covalent drug-matrix interactions (Appel et al., 2015; Li and Mooney, 2016; Ruskowitz and DeForest, 2018; Narayanaswamy and Torchilin, 2019). Noncovalent interactions include electrostatic interactions such as heparin and heparin binding proteins (Liang and Kiick, 2014; Freudenberg et al., 2016), or hydrophobic associations such as cyclodextrin and hydrophobic drugs (Mateen and Hoare, 2014). Otherwise, covalent interactions can be designed using noncleavable and cleavable linkages between drugs and hydrogels that are incorporated via reactions such as click chemistries (e.g., copper-free click, thiol-ene, Diels-Alder reactions, and oxime and hydrazine ligation) and photochemistries (e.g., nitrobenzyl and coumarin photocleavage reactions); these reactions also are employed for hydrogel crosslinking (Christman et al., 2011; Yigit et al., 2011; Phelps et al., 2012; Ulrich et al., 2014; Kolmel and Kool, 2017; Ruskowitz and DeForest, 2018; Palmese et al., 2019). Thus, the chemical tunability of hydrogels, particularly their mesh size, crosslinking chemistry, and drug interactions, enables fine-tuned control over drug transport through the hydrogel.

\section{Simple Diffusion}

Extracellular matrix-based hydrogels for local drug delivery not only support cells biochemically and mechanically through cell-matrix interactions, but also release the drugs into infiltrated cells. Since the hydrogel is formed by the 
crosslinked polymer network, the mesh space between polymer chains allows the diffusion of liquid and small molecules (Li and Mooney, 2016). Depending on the mesh size of a hydrogel, small molecule drugs can diffuse through the hydrogel and be released from the hydrogel for delivery to the surrounding cells.

Due to its structural properties, collagen is often utilized as the matrix for local drug delivery. A type I collagen matrix on the surface of polyurethane films enhanced fibroblast attachment, proliferation, and growth (Park et al., 2000). While collagen matrices provide a physiologically inspired microenvironment to cells, collagen also can control the delivery of drugs such as small molecules, proteins, and genes via simple diffusion and/or biodegradation. Collagen matrices have been loaded with a variety of small molecules such as antibiotics for wound care, cisplatin for local cancer therapy, and anti-inflammatory reagents for tissue regeneration in ophthalmology (Zilberman and Elsner, 2008; De Souza et al., 2010; Duxfield et al., 2016). Small molecule gentamicin-eluting collagen matrix [Collatamp ${ }^{\circledR}$ (Schering-Plough, Stockholm, Sweden), Sulmycin ${ }^{\circledR}$-Implant (Schering-Plough, United States), and Septocoll ${ }^{\circledR}$ (Biomet Merck, Germany)] have been used in the clinic as wound care products to promote both granulation tissue formation and epithelialization, and to protect tissues from potential infection (de Bruin et al., 2010; Raja, 2012; Chia et al., 2014).

In addition to small molecule delivery, proteins such as growth factors can be loaded into the collagen matrix; for example the delivery of bone morphogenetic protein (BMP) from a collagen matrix has been shown to promote bone formation. Recombinant human BMP-2 (rhBMP-2)-loaded collagen matrices (INFUSE ${ }^{\circledR}$ bone graft and MASTERGRAFT ${ }^{\circledR}$ ) are available in the clinic to treat bone fracture and spinal fusion (Li and Mooney, 2016). Clinical trials using INFUSE ${ }^{\circledR}$ in spinal orthopedic trauma, and oral maxillofacial applications have demonstrated the efficacy of INFUSE $^{\circledR}$ to form de novo bone (Figure 3A; McKay et al., 2007). The Garcia group created a collagen mimetic peptide (GFOGER)-modified PEG synthetic hydrogel to deliver BMP-2 to murine radial critical-sized defects (Shekaran et al., 2014). The GFOGERmodified hydrogel increased osteoprogenitor localization in the defect site and sustained release of BMP-2 to enhance bone formation and healing. In addition, the Garcia group investigated RGD and GFOGER-modified PEG synthetic hydrogels for the delivery of lysostaphin to treat Staphylococcus aureus infections in bone fractures (Figure 3B; Johnson et al., 2018). Based on histological analysis, lysostaphin delivery using the RGD/GFOGER-based PEG hydrogel system (UAMS$1+$ Lst) demonstrated the ability of the system to reduce bacterial infection compared to the non-treatment control (UAMS-1), and these materials were shown to promote fracture repair of femoral bone in mouse such that the resulting healed tissue was similar to sterile positive control groups. A lysostaphin solution without hydrogel (UAMS$1+$ Sol.) failed both in reducing bacterial infection and in improving bone repair. ECM-based hydrogel matrices create a microenvironment conductive to supporting growth of recruited cells while also controlling drug release to enhance tissue regeneration.

\section{ECM-Based Matrix and Drug/Carrier Interactions}

Drug release from ECM-based matrix is also dependent upon drug-ECM interactions. Electrostatic and hydrophobic attractive forces between drug molecules and ECM molecules can reduce and/or prohibit drug diffusion through the network, leading to prolonged drug retention and alternate controlling parameters for release from the matrix. The electrostatic interactions between highly negative polysaccharides and drugs are employed in the sustained delivery/retention of many drugs. For example, Cool and colleagues validated the delivery efficacy of BMP-2 using thiol-modified hyaluronan (Glycosil ${ }^{\mathrm{TM}}$ ), and these materials were compared to collagen sponges (e.g., as a mimic of INFUSE ${ }^{\circledR}$ bone grafts) in terms of their influence on ectopic bone formation (Bhakta et al., 2013). The electrostatic interaction between BMP2 and negatively charged hyaluronic acid hydrogels resulted in a low burst followed by sustained release of BMP-2, whereas collagen hydrogels showed high burst and sustained release of BMP-2. The low burst and sustained release of BMP-2 from hyaluronic acid hydrogels improved the bone formation to the greatest extent in a rat intramuscular ectopic model.

Moreover, due to the ability of ECM molecules to interact with growth factors, ECM molecules are utilized in DDS for the sustained release of growth factors from hydrogel matrices. In particular, heparin-based hydrogels have been widely employed as growth factor carriers for tissue regeneration (Sakiyama-Elbert and Hubbell, 2000; Tanihara et al., 2001; Jeong and Panitch, 2009; Liang and Kiick, 2014; Freudenberg et al., 2016). Netti and coworkers developed porous PEG-heparin hydrogels encapsulating the angiogenic growth factor VEGF. Because of the interaction between heparin and VEGF, VEGF was released in a controlled manner and the released VEGF promoted angiogenesis in vivo (Oliviero et al., 2012). Also, the Werner group investigated RGD-functionalized star PEG-heparin hydrogels with a variable degree of heparin sulfation for controlled release of angiogenic growth factors from the hydrogel and capture of inflammatory chemokines in the hydrogel for the chronic wound healing applications (Freudenberg et al., 2015; Lohmann et al., 2017). In addition, the Hubbell group developed laminin-mimetic peptides, which include heparin-binding domains, and employed them to decorate a fibrin matrix for the delivery of VEGFA165 and platelet derived growth factor PDGF-BB in a chronic wound treatment application (Ishihara et al., 2018). Since the heparin-binding domain in laminin-mimetic peptides has a strong affinity to syndecan cell surface receptors, as well as to VEGF-A165 and PDGF-BB, the system enhanced cell adhesion through interaction with syndecan, and also enabled the sustained release of growth factors from the matrix (Figure 4A). This resulted in promotion of wound healing in a type2 diabetic mouse. With a similar approach, the Christman group applied decellularized ECM-derived hydrogels in heparinbinding growth factor delivery systems for tissue regeneration in the post-myocardial infarction (Seif-Naraghi et al., 2012). 


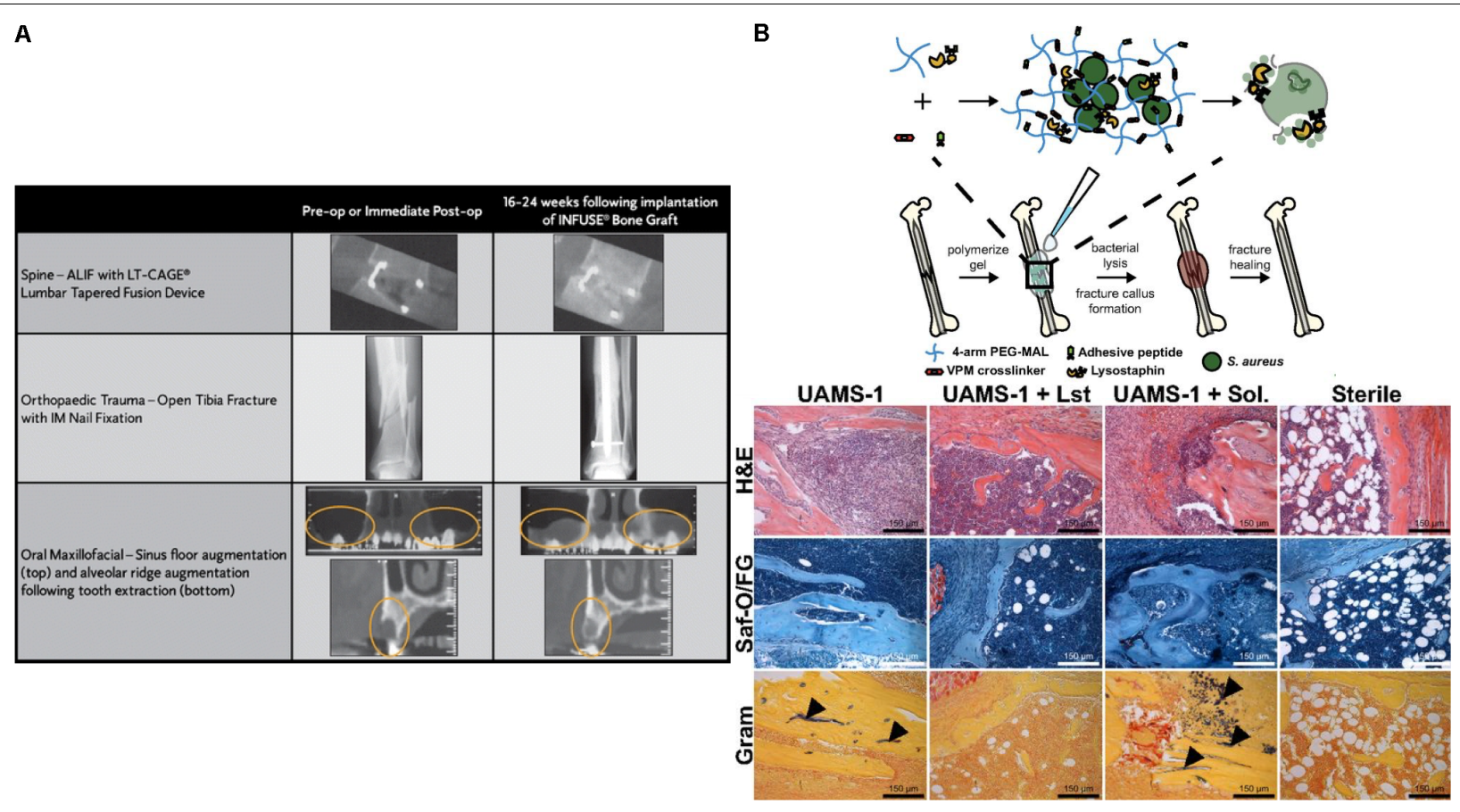

FIGURE 3 | Simple diffusion of drugs from ECM based matrices. (A) Computed tomography (CT) images for the efficacy of INFUSE ${ }^{\circledR}$ Bone Graft in clinical applications (McKay et al., 2007). Copyright 2007. Reproduced with permission from Springer Nature. (B) The scheme of overall study design. Histologic analysis using H\&E, Saf-O/FG, and Gram staining of femurs after treating with hydrogel (UAMS-1), Lysostaphin-delivering hydrogel (UAMS-1 + Lst), and Lysostaphin, and sterilization (Johnson et al., 2018). Copyright 2018. Reproduced with permission from the National Academy of Sciences.

Porcine pericardia were decellularized using $1 \%$ SDS and digested with pepsin to prepare decellularized ECM-derived hydrogel with intact native sulfated glycosaminoglycans (PPM). Plasmid DNA encoding fibroblast growth factors (pFGF) in PPM injected into rats with post-myocardial infarction was still retained in the tissue after 5 days of administration, and the amount of pFGF retained was greater than the amount of bFGF retained in collagen hydrogels or in saline.

While controlled drug release via drug-ECM interactions is a powerful strategy to improve retention and sustained delivery, existing examples are mostly limited to the use of heparinbinding growth factors and charged molecules. To address this limitation, as described above, active peptide sequences from various ECM proteins have been identified and exploited in controlling the drug release from ECM-based matrices. Chemical modifications of the active sequences and their attachment to drugs or polymeric carriers enable immobilization in ECM-based hydrogel matrices for sustained drug release. Rolle and coworkers utilized a collagen-binding domain ( $\mathrm{CCBD}$ derived from collagenase or fCBD derived from fibronectin) to tether synthetic human antimicrobial peptides, catelicidin LL37, on collagen scaffolds for treatment of wound infection (Figure 4B; Lozeau et al., 2017). Even after 14 days, LL37 with collagen domains (cCBD-LL37 and fCBD-LL37) was still retained on the collagen scaffold and showed similar levels of antimicrobial activity after $12 \mathrm{~h}$. However, due to the burst release of LL37 from collagen scaffold, the antimicrobial activity of LL37-loaded collagen scaffolds was reduced at 14 days compared to $12 \mathrm{~h}$. In another example, the Hubbell group developed strategies for the delivery and release of both immune checkpoint inhibitor antibodies $(\alpha \mathrm{CTLA} 4+\alpha \mathrm{PD}-\mathrm{L} 1)$ and interleukin-2 (IL-2) using collagenbinding domains (CBDs) derived from the von Willebrand factor (vWF) A3 domain to immobilize drugs on collagen in the tumor stroma for cancer immunotherapy (Ishihara et al., 2019). Systemically administered CBD-tumor drug conjugates mainly accumulated in the tumor sites in murine cancer models, whereas non-CBD modified drugs did not. Drug delivery and release from the tumor collagen matrix-DDS interaction improved safety by eliminating antibody hepatotoxicity and by ameliorating pulmonary edema by IL-2, and it also improved efficacy through reducing the size of tumor. Overall, these examples demonstrate that the immobilization of therapeutic agents on the matrix using peptides prolongs the effectiveness of the therapeutic agents via controlled release from the scaffold.

\section{ECM-Based Matrix and Carrier Interaction for Intracellular Delivery}

Drug delivery systems that combine these two approaches, e.g., immobilizing a drug in an ECM-based hydrogel and exploiting ECM-mediated cell uptake, have demonstrated enhanced therapeutic efficacy. In particular, this hybrid strategy will have enormous benefit on the delivery of intracellular therapeutic agents such as nucleic acids, which require DDS to facilitate cellular internalization and prevent the degradation of nucleic acids in the extra- and intracellular environments 

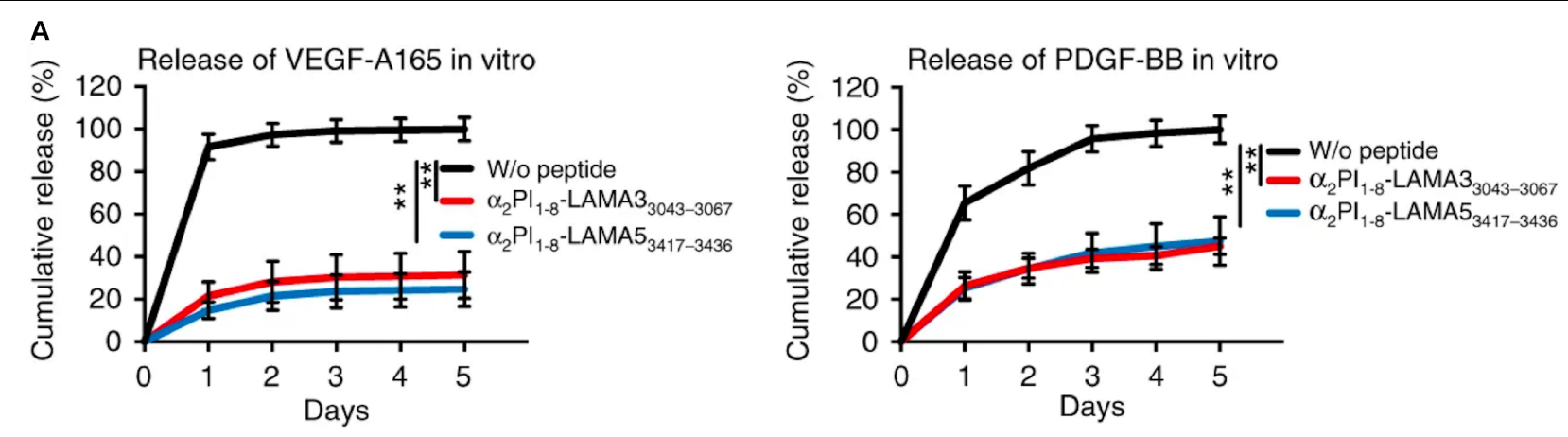

B
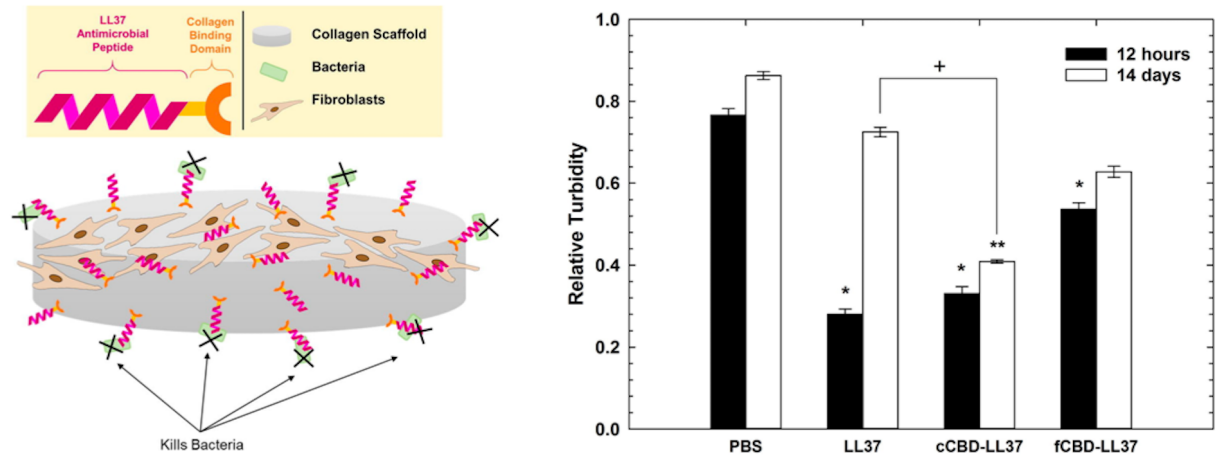

FIGURE 4 | Extracellular matrix-based matrices and drug interaction-based delivery systems. (A) Growth factor retention in fibrin matrices with laminin-mimetic peptides ( $\alpha 2$ PI1-8-LAMA33043-3067 or $\alpha 2$ PI1-8-LAMA53417-3436) or without peptide (** $<0.01$ ) (Ishihara et al., 2018). Copyright 2018. Reproduced with permission from Springer Nature. (B) The scheme of study design. Antimicrobial activity of LL37 and with collagen-binding domains (cCBD-LL37 or fCBD-LL37) on collagen scaffold after $12 \mathrm{~h}$ and 14 days $\left({ }^{*} p<0.01,{ }^{* *} p<0.001,{ }^{+} p<0.05\right.$ ) (Lozeau et al., 2017). Copyright 2017. Reproduced with permission from Elsevier Inc.

before they transfer to the appropriate cellular compartment. BMP-delivery systems using ECM-based hydrogels (INFUSE, MASTERGRAFT, OP-1) are clinically available. However, gene delivery systems often fail to meet their clinical potential due to their relative low transfection efficiency and off-target expression (Al-Dosari and Gao, 2009; Li and Mooney, 2016). The ideal gene delivery system in tissue regeneration applications should be able to sustain the delivery of active genes throughout the tissue formation process. Thus, immobilization of gene carriers in ECM-based hydrogels has the potential to achieve sustained delivery in response to cell-secreted proteases that are present during tissue repair and regeneration process, and the subsequent targeted cell uptake mediated by cell-receptor/ECM interactions.

Polymer and DNA complexes (polyplexes) have been encapsulated into scaffolds through non-specific and specific interactions between the complex and scaffold, leading to sustained DNA release from the matrix (De Laporte and Shea, 2007; Wang and Gao, 2014). Collagen-based matrix has been widely utilized to incorporate DNA complexes via nonspecific interactions with the matrix to promote skin tissue repair and bone regeneration applications (Mao et al., 2009; Elangovan et al., 2014). For example, Gao and co-workers demonstrated the incorporation of cationic trimethylchitosan chloride (TMC) and DNA encoding VEGF-165 complex into the collagen-chitosan/silicone membrane bilayer dermal scaffold (TMC/pDNA-VEGF complexes loaded scaffold) to enhance angiogenesis for wound repair applications (Guo et al., 2010).
Immunohistological analysis, RT-qPCR, and Western blotting analysis showed that the TMC/pDNA-VEGF complex-loaded scaffold was able to promote wound healing in incisional porcine wounds via VEGF-driven angiogenesis. The Salem group explored the delivery of polyethylenimine (PEI) and DNA encoding PDGF-B complex (Polyplex-PDGF-B) using collagen scaffolds for bone regeneration (Elangovan et al., 2014). In vivo studies using a calvarial defect rat model revealed that after 4 weeks of sample implantation, polyplex-PDGF-B in collagen promoted significantly higher new bone formation as compared to collagen-only scaffold, suggesting the effective approach and potential clinical translation for bone regeneration.

Polyplexes also have been incorporated into the matrix via specific interactions between polyplex and matrix. Netti et al. developed gene-activated matrices through immobilization of biotin-polyethylenimine (PEI) and DNA complexes (polyplexes) in avidin-functionalized collagen matrix (Orsi et al., 2010). The immobilized polyplexes provided higher bioavailability to NIH3T3 cells recruited into the collagen matrix. The use of avidin-biotin interactions increased the transfection efficiency by approximately two-fold as compared polyplexes in collagen matrix lacking avidin-biotin linkages (Figure 5A). Moreover, Segura and co-workers recently investigated electrostatically immobilized PEI/DNA complexes (polyplexes) in porous hyaluronic acid hydrogels (Truong and Segura, 2018). The hydrogel formulation approach reduced the cytotoxicity of the polyplexes in murine mesenchymal 


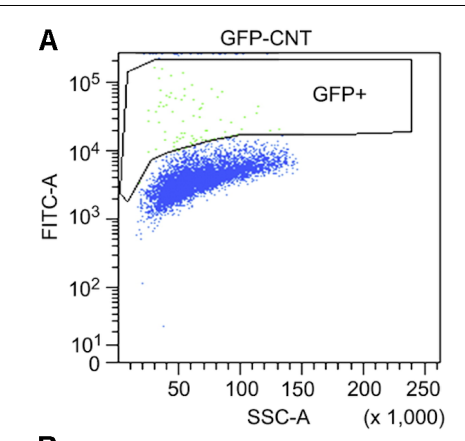

B

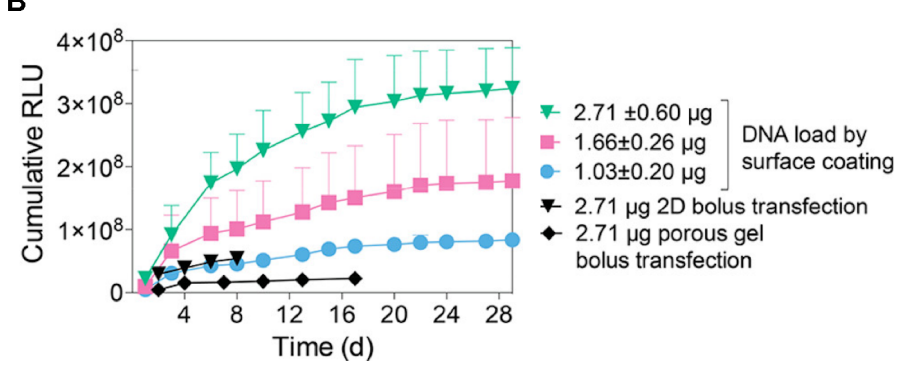

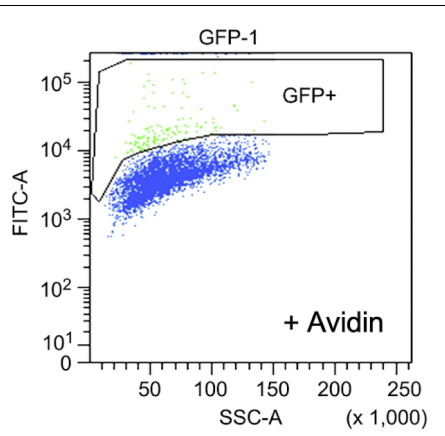

D

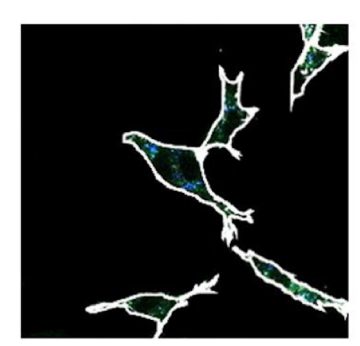

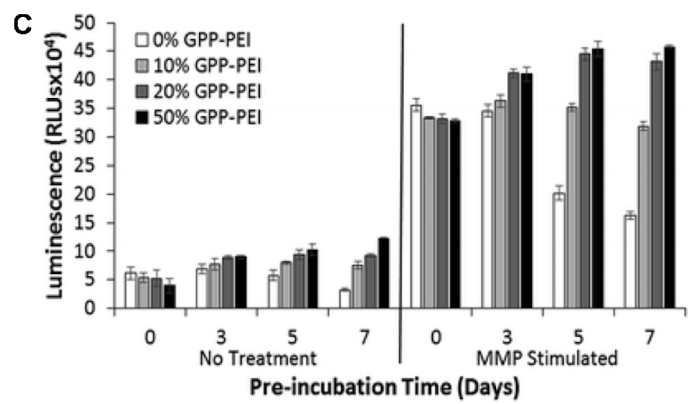

$20 \%$ GPP-PEI

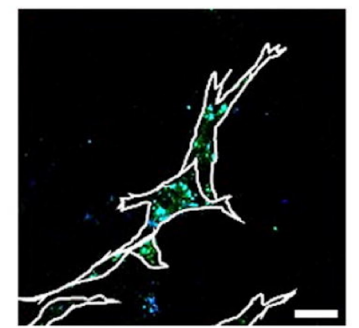

FIGURE 5 | Polyplex immobilized in an ECM-based matrix for gene delivery. (A) Flow-activated cell sorting (FACS) analysis of biotin-functionalized pGFP polyplex immobilized in avidin-modified collagen hydrogel through avidin-biotin interaction (right graph) and avidin-free collagen hydrogel (left) (Orsi et al., 2010). Copyright 2010. Reproduced with permission from Elsevier Inc. (B) pGluc expression for 30 days of cell culture in the presence of immobilized pGluc polyplex on the surface of hyaluronic acid hydrogel through electrostatic interaction, and bolus transfection controls (Truong and Segura, 2018). Copyright 2018. Reproduced with permission from the American Chemical Society. (C) pGluc expression of immobilized GPP-PEl in the collagen hydrogel and free GPP polyplex in hydrogel after a week of pre-incubation in media with and without the presence of metalloproteinase (Urello et al., 2014). Copyright 2014. Reproduced with permission from The Royal Society of Chemistry. (D) Colocalization study of FITC labeled collagen (Green) with Alexa Fluor 350 labeled GPP-PEl (Blue) in NIH3T3 cells after 5 days of pre-incubation in the media (Urello et al., 2017). The scale bar is $25 \mu \mathrm{m}$. Copyright 2017. Reproduced with permission from Elsevier Inc.

stem cells as compared to $2 \mathrm{D}$ bolus transfections with multiple doses. These observations suggested that the immobilized polyplex on the hydrogel enhanced and sustained the transgene expression over 30 days of cell culture, compared to a non-coated bolus transfection (Figure 5B). In addition to these two strategies for non-covalent immobilization of poyplex to ECM hydrogels, our group has developed approaches to immobilize polyplexes in collagen hydrogels through interactions with collagen-mimetic peptides [e.g., GPP: (GPP) $)_{3}$ GPRGEKGERGPR(GPP) ${ }_{3}$ GPCCG] that have affinity for native collagen through strand invasion and triple-helical binding (Urello et al., 2014, 2016, 2017). With higher amounts of GPP incorporated in the polyplex, the polyplex was retained in the hydrogel longer, with retention up to 35 days (Urello et al., 2014). In addition, GPP-modified PEI polyplexes, after a week of pre-incubation within collagen hydrogels in media, still showed greater gene expression by murine fibroblasts compared to GPP-free polyplexes. In particular, gene transfer in MMP-stimulated cells was highly robust, suggesting potential treatment options for chronic inflammatory diseases such as chronic wounds (Figure 5C). A collagen-polyplex colocalization study revealed that the GPP-PEI, along with collagen fragments, were internalized in cells largely via caveolar endocytosis, suggesting integrin interaction with the integrin-binding sites of collagen fragments are involved in cellular internalization (Figure 5D; Urello et al., 2017).
GPP-PEI and collagen hydrogel interactions allowed both the controlled release and ligand-mediated efficient endocytosis into cells.

\section{SUMMARY AND FUTURE PROSPECTS}

For the past several decades, significant progress has been made in the development of targeted DDS using both local administration and ligand-based active targeting strategies. Hydrogel-based local delivery and ligand-cell interactionmediated delivery enable drugs such as biomacromolecules (e.g., growth factors or genes) and small molecules to better localize at the target sites. Owing to the biological versatility of ECM molecules, ECM-based DDS have been applied not only to provide structural and biochemical signals to cells, but also to serve as ligands for cell receptors in specific pathological conditions to improve therapeutic efficacy of growth factor, gene, and small molecule treatments. However, despite progressive improvements, many challenges and unmet clinical needs still remain, particularly for intracellularly active drugs such as genes, which require control over cellular uptake mechanisms for optimized delivery and activity.

The innovative combination of these two targeting approaches using immobilizing drug carriers in ECM-based hydrogels has generated promising cell-responsive gene-activated matrices for 
regenerative medicine and functional tissue repair. ECM scaffolds not only function as substrates for cell infiltration, organization, and differentiation, but also enable resident cells to efficiently uptake genes on demand to supply essential tissue inductive factors. However, many challenges remain in further developing this type of DDS to, for example, enable the delivery of multiple drugs from a single system, or provide mechanisms for ondemand drug release with a high level of control to a specific cell type. The sequential signaling of multiple growth factors typically regulates tissue repair and regeneration. Although researchers have demonstrated the release of multiple drugs, obtaining release of a specific molecule with optimal timing remains a challenge. Further, despite the advances in targeting, materials that localize only at or in their target cells are still difficult to design due to the lack of cell-specific gene expression relevant to a given disease physiology. Use of multiple ECM-inspired peptides in conjunction may offer a promising strategy to increase affinity to a particular cell type, using information about the cell's natural ECM receptor expression patterns, or to promote the sequential delivery of a series of drugs in a desired profile. In the future, ECM

\section{REFERENCES}

Aderem, A., and Underhill, D. M. (1999). Mechanisms of phagocytosis in macrophages. Annu. Rev. Immunol. 17, 593-623. doi: 10.1146/annurev. immunol.17.1.593

Alam, N., Goel, H. L., Zarif, M. J., Butterfield, J. E., Perkins, H. M., Sansoucy, B. G., et al. (2007). The integrin-growth factor receptor duet. J. Cell Physiol. 213, 649-653. doi: 10.1002/jcp. 21278

Al-Dosari, M. S., and Gao, X. (2009). Nonviral gene delivery: principle, limitations, and recent progress. AAPS J. 11, 671-681. doi: 10.1208/s12248-009-9143-y

Allen, T. M., and Cullis, P. R. (2004). Drug delivery systems: entering the mainstream. Science 303, 1818-1822. doi: 10.1126/science.1095833

An, B., and Brodsky, B. (2016). Collagen binding to OSCAR: the odd couple. Blood 127, 521-522. doi: 10.1182/blood-2015-12-682476

Appel, E. A., Tibbitt, M. W., Webber, M. J., Mattix, B. A., Veiseh, O., and Langer, R. (2015). Self-assembled hydrogels utilizing polymer-nanoparticle interactions. Nat. Commun. 6:6295. doi: 10.1038/ncomms7295

Arap, W., Pasqualini, R., and Ruoslahti, E. (1998). Cancer treatment by targeted drug delivery to tumor vasculature in a mouse model. Science $279,377-380$. doi: 10.1126/science.279.5349.377

Arora, P. D., Wang, Y., Bresnick, A., Dawson, J., and Janmey, P. A. (2013). Collagen remodeling by phagocytosis is determined by collagen substrate topology and calcium-dependent interactions of gelsolin with nonmuscle myosin IIA in cell adhesions. Mol. Biol. Cell 24, 734-747. doi: 10.1091/mbc.E12-10-0754

Belting, M. (2003). Heparan sulfate proteoglycan as a plasma membrane carrier. Trends Biochem. Sci. 28, 145-151. doi: 10.1016/S0968-0004(03)00031-8

Benton, G., Arnaoutova, I., George, J., Kleinman, H. K., and Koblinski, J. (2014). Matrigel: from discovery and ECM mimicry to assays and models for cancer research. Adv. Drug Deliv. Rev. 7, 3-18. doi: 10.1016/j.addr.2014.06.005

Bhakta, G., Lim, Z. X., Rai, B., Lin, T., Hui, J. H., Prestwich, G. D., et al. (2013). The influence of collagen and hyaluronan matrices on the delivery and bioactivity of bone morphogenetic protein-2 and ectopic bone formation. Acta Biomater. 9, 9098-9106. doi: 10.1016/j.actbio.2013.07.008

Bibby, D. C., Talmadge, J. E., Dalal, M. K., Kurz, S. G., Chytil, K. M., Barry, S. E., et al., (2005). Pharmacokinetics and biodistribution of RGD-targeted doxorubicin-loaded nanoparticles in tumor-bearing mice. Int. J. Pharm. 293, 281-290. doi: 10.1016/j.ijpharm.2004.12.021

Blanco, E., Shen, H., and Ferrari, M. (2015). Principles of nanoparticle design for overcoming biological barriers to drug delivery. Nat. Biotechnol. 33, 941-951. doi: $10.1038 /$ nbt. 3330 molecule-based DDS are likely to have an increasingly significant impact on disease treatment and tissue regeneration.

\section{AUTHOR CONTRIBUTIONS}

All authors conceived the layout, the rationale, and the plan of this manuscript. JH wrote the first draft of the manuscript that was iteratively improved by MS and KK.

\section{FUNDING}

Related work in the authors' laboratories was supported by the National Institutes of Health (NIH RO1 AR067247, NIH R21 AR069778, and NIH P30GM110758) and the National Science Foundation (NSF PFI1700980, NSF CBET1159466, and NSF 1605130) awarded to MS and KK. The views expressed here are the responsibility of the authors and do not necessarily reflect the position of the funding agencies.

Boekhoven, J., and Stupp, S. I. (2014). 25th anniversary article: supramolecular materials for regenerative medicine. Adv. Mater. 26, 1642-1659. doi: 10.1002/ adma.201304606

Cai, L., and Heilshorn, S. C. (2014). Designing ECM-mimetic materials using protein engineering. Acta Biomater. 10, 1751-1760. doi: 10.1016/j.actbio.2013. 12.028

Caliari, S. R., and Burdick, J. A. (2016). A practical guide to hydrogels for cell culture. Nat. Methods 13, 405-414. doi: 10.1038/nmeth.3839

Carvalho, R. M., Carvalho, R. C., Maia, R. F., Caballero, D., Kundu, C. S., Reis, L. R., et al. (2019). Peptide-modified dendrimer nanoparticles for targeted therapy of colorectal cancer. Adv. Ther. 2:1900132. doi: 10.1002/adtp.201900132

Cervadoro, A., Palomba, R., Vergaro, G., Cecchi, R., Menichetti, L., Decuzzi, P., et al. (2018). Targeting inflammation with nanosized drug delivery platforms in cardiovascular diseases: immune cell modulation in atherosclerosis. Front. Bioeng. Biotechnol. 6:177. doi: 10.3389/fbioe.2018.00177

Chia, C. L., Shelat, V. G., Low, W., George, S., and Rao, J. (2014). The use of Collatamp G, local gentamicin-collagen sponge, in reducing wound infection. Int. Surg. 99, 565-570. doi: 10.9738/INTSURG-D-1300171.1

Chowdhury, E. H., and Akaike, T. (2006). Fibronectin-coated nano-precipitates of calcium-magnesium phosphate for integrin-targeted gene delivery. J. Control Release 116:e68-e69. doi: 10.1016/j.jconrel.2006.09.054

Christianson, H. C., and Belting, M. (2014). Heparan sulfate proteoglycan as a cellsurface endocytosis receptor. Matrix Biol. 35, 51-55. doi: 10.1016/j.matbio.2013. 10.004

Christman, K. L., Broyer, R. M., Schopf, E., Kolodziej, C. M., Chen, Y., Maynard, H. D., et al. (2011). Protein nanopatterns by oxime bond formation. Langmuir 27, 1415-1418. doi: 10.1021/la103978x

Chung, Y. I., Kim, J. C., Kim, Y. H., Tae, G., Lee, S. Y., Kim, K., et al. (2010). The effect of surface functionalization of PLGA nanoparticles by heparinor chitosan-conjugated Pluronic on tumor targeting. J. Control Release 143, 374-382. doi: 10.1016/j.jconrel.2010.01.017

Cichy, J., and Pure, E. (2003). The liberation of CD44. J. Cell Biol. 161, 839-843. doi: $10.1083 /$ jcb.200302098

Colognato, H., and Yurchenco, P. D. (2000). Form and function: the laminin family of heterotrimers. Dev. Dyn. 218, 213-234.

Coopman, P. J., Thomas, D. M., Gehlsen, K. R., and Mueller, S. C. (1996). Integrin alpha 3 beta 1 participates in the phagocytosis of extracellular matrix molecules by human breast cancer cells. Mol. Biol. Cell 7, 1789-1804. doi: 10.1091/mbc.7. 11.1789 
Crapo, P. M., Gilbert, T. W., and Badylak, S. F. (2011). An overview of tissue and whole organ decellularization processes. Biomaterials 32, 3233-3243. doi: 10.1016/j.biomaterials.2011.01.057

Danhier, F., Feron, O., and Preat, V. (2010). To exploit the tumor microenvironment: Passive and active tumor targeting of nanocarriers for anti-cancer drug delivery. J. Control Release 148, 135-146. doi: 10.1016/j.jconrel.2010.08.027

Danhier, F., Le Breton, A., and Preat, V. (2012). RGD-based strategies to target alpha(v) beta(3) integrin in cancer therapy and diagnosis. Mol. Pharm. 9, 2961-2973. doi: 10.1021/mp3002733

Das, L., Anderson, T. A., Gard, J. M., Sroka, I. C., Strautman, S. R., Nagle, R. B., et al. (2017). Characterization of laminin binding integrin internalization in prostate cancer cells. J. Cell Biochem. 118, 1038-1049. doi: 10.1002/jcb.25673

de Bruin, A. F., Gosselink, M. P., van, der Harst, E., and Rutten, H. J. (2010). Local application of gentamicin collagen implants in the prophylaxis of surgical site infections following gastrointestinal surgery: a review of clinical experience. Tech. Coloproctol. 14, 301-310. doi: 10.1007/s10151-010-0593-0

De Laporte, L., and Shea, L. D. (2007). Matrices and scaffolds for DNA delivery in tissue engineering. Adv. Drug Deliv. Rev. 59, 292-307. doi: 10.1016/j.addr.2007. 03.017

De Souza, R., Zahedi, P., Allen, C. J., and Piquette-Miller, M. (2010). Polymeric drug delivery systems for localized cancer chemotherapy. Drug Deliv. 17, 365-375. doi: 10.3109003762854

Dimatteo, R., Darling, N. J., and Segura, T. (2018). In situ forming injectable hydrogels for drug delivery and wound repair. Adv. Drug Deliv. Rev. 127, 167-184. doi: 10.1016/j.addr.2018.03.007

Dosio, F., Arpicco, S., Stella, B., and Fattal, E. (2016). Hyaluronic acid for anticancer drug and nucleic acid delivery. Adv. Drug Deliv. Rev. 97, 204-236. doi: 10.1016/ j.addr.2015.11.011

D'Souza, A. A., and Devarajan, P. V. (2015). Asialoglycoprotein receptor mediated hepatocyte targeting - strategies and applications. J. Control Release 203, 126139. doi: 10.1016/j.jconrel.2015.02.022

Dubey, P. K., Singodia, D., and Vyas, S. P. (2010). . Polymeric nanospheres modified with YIGSR peptide for tumor targeting. Drug. Deliv. 17, 541-551. doi: 10.3109.2010.490249

Dunehoo, A. L., Anderson, M., Majumdar, S., Kobayashi, N., Berkland, C., et al. (2006). Cell adhesion molecules for targeted drug delivery. J. Pharm. Sci. 95, 1856-1872. doi: 10.1002/jps.20676

Duxfield, L., Sultana, R., Wang, R., Englebretsen, V., Deo, S., Rupenthal, I. D., et al. (2016). . Ocular delivery systems for topical application of anti-infective agents. Drug. Dev. Ind. Pharm. 42, 1-11. doi: 10.3109.2015.1070171

Elangovan, S., D’Mello, S. R., Hong, L., Ross, R. D., Allamargot, C., Dawson, D. V., et al. (2014). The enhancement of bone regeneration by gene activated matrix encoding for platelet derived growth factor. Biomaterials 35, 737-747. doi: 10.1016/j.biomaterials.2013.10.021

Eliaz, R. E., and Szoka, F. C. Jr. (2001). Liposome-encapsulated doxorubicin targeted to CD44: a strategy to kill CD44-overexpressing tumor cells. Cancer Res. 61, 2592-2601.

El-Sayed, A., and Harashima, H. (2013). Endocytosis of gene delivery vectors: from clathrin-dependent to lipid raft-mediated endocytosis. Mol. Ther. 21, 1118-1130. doi: 10.1038/mt.2013.54

Fan, Y., Yao, J., Du, R., Hou, L., Zhou, J., Lu, Y., et al. (2013). Ternary complexes with core-shell bilayer for double level targeted gene delivery: in vitro and in vivo evaluation. Pharm. Res. 30, 1215-1227. doi: 10.1007/s11095-012-0960-9

Farajzadeh, R., Zarghami, N., Serati-Nouri, H., Momeni-Javid, Z., Farajzadeh, T., and Jalilzadeh-Tabrizi, S. (2018). Macrophage repolarization using CD44targeting hyaluronic acid-polylactide nanoparticles containing curcumin. Artif. Cells Nanomed Biotechnol. 46, 2013-2021. doi: 10.1080.2017.1408116

Farrukh, A., Ortega, F., Fan, W., Marichal, N., Paez, J. I., Berninger, B., et al. (2017). Bifunctional hydrogels containing the laminin Motif IKVAV promote neurogenesis. Stem Cell Rep. 9, 1432-1440. doi: 10.1016/j.stemcr.2017.09.002

Foroozandeh, P., and Aziz, A. A. (2018). Insight into cellular uptake and intracellular trafficking of nanoparticles. Nanoscale Res. Lett. 13:339. doi: 10. 1186/s11671-018-2728-6

Freudenberg, U., Liang, Y., Kiick, K. L., and Werner, C. (2016). Glycosaminoglycan-based biohybrid hydrogels: a sweet and smart choice for multifunctional biomaterials. Adv. Mater. 28, 8861-8891. doi: 10.1002/adma.201601908
Freudenberg, U., Zieris, A., Chwalek, K., Tsurkan, M. V., Maitz, M. F., Atallah, P., et al. (2015). Heparin desulfation modulates VEGF release and angiogenesis in diabetic wounds. J. Control Release 220(Pt A), 79-88. doi: 10.1016/j.jconrel. 2015.10.028

Fu, S., Xu, X., Ma, Y., Zhang, S., and Zhang, S. (2019). RGD peptide-based non-viral gene delivery vectors targeting integrin alphavbeta3 for cancer therapy. J. Drug. Target. 27, 1-11. doi: 10.1080/1061186X.2018.1455841

Garber, K. (2018). Alnylam launches era of RNAi drugs. Nat. Biotechnol. 36, 777-778. doi: 10.1038/nbt0918-777

Giancotti, F. G. (2003). A structural view of integrin activation and signaling. Dev. Cell 4, 149-151.

Giancotti, F. G., and Ruoslahti, E. (1999). Integrin signaling. Science 285, 10281032. doi: 10.1126/science.285.5430.1028

Goebeler, M., Kaufmann, D., Brocker, E. B., and Klein, C. E. (1996). Migration of highly aggressive melanoma cells on hyaluronic acid is associated with functional changes, increased turnover and shedding of CD44 receptors. J. Cell Sci. 109(Pt 7), 1957-1964.

Goodman, S. L., and Picard, M. (2012). Integrins as therapeutic targets. Trends Pharmacol. Sci. 33, 405-412. doi: 10.1016/j.tips.2012.04.002

Gospodarowicz, D., and Cheng, J. (1986). Heparin protects basic and acidic FGF from inactivation. J. Cell Physiol. 128, 475-484. doi: 10.1002/jcp.1041280317 13528177

Graf, J., Iwamoto, Y., Sasaki, M., Martin, G. R., Kleinman, H. K., Robey, F. A., et al. (1987). Identification of an amino acid sequence in laminin mediating cell attachment, chemotaxis, and receptor binding. Cell 48, 989-996. doi: 10.1016/ 0092-8674(87)90707-0/2951015

Guo, R., Xu, S., Ma, L., Huang, A., and Gao, C. (2010). Enhanced angiogenesis of gene-activated dermal equivalent for treatment of full thickness incisional wounds in a porcine model. Biomaterials 31, 7308-7320. doi: 10.1016/j. biomaterials.2010.06.013

Hamano, N., Negishi, Y., Fujisawa, A., Manandhar, M., Sato, H., Katagiri, F., et al. (2012). Modification of the C16Y peptide on nanoparticles is an effective approach to target endothelial and cancer cells via the integrin receptor. Int. J. Pharm. 428, 114-117. doi: 10.1016/j.ijpharm.2012.02.006

Harburger, D. S., and Calderwood, D. A. (2009). Integrin signalling at a glance. J. Cell Sci. 122(Pt 2), 159-163. doi: 10.1242/jcs.018093

Hendricks, M. P., Sato, K., Palmer, L. C., and Stupp, S. I. (2017). Supramolecular Assembly of Peptide Amphiphiles. Acc. Chem. Res. 50, 2440-2448. doi: 10.1021/ acs.accounts.7b00297

Hernandez, J. M., Gaetani, R., Pieters, M. V., Ng, W. N., Chang, E. A., Martin, T. R., et al. (2018). Decellularized extracellular matrix hydrogels as a delivery platform for MicroRNA and extracellular vesicle therapeutics. Adv. Ther. 1: 1800032 .

Highley, C. B., Prestwich, G. D., and Burdick, J. A. (2016). Recent advances in hyaluronic acid hydrogels for biomedical applications. Curr. Opin. Biotechnol. 40, 35-40. doi: 10.1016/j.copbio.2016.02.008

Hinderer, S., Layland, S. L., and Schenke-Layland, K. (2016). ECM and ECMlike materials - Biomaterials for applications in regenerative medicine and cancer therapy. Adv. Drug. Deliv. Rev. 97, 260-269. doi: 10.1016/j.addr.2015. 11.019

Hoffman, M. P., Engbring, J. A., Nielsen, P. K., Vargas, J., Steinberg, Z., Karmand, A. J., et al. (2001). Cell type-specific differences in glycosaminoglycans modulate the biological activity of a heparin-binding peptide (RKRLQVQLSIRT) from the G domain of the laminin alphal chain. J. Biol. Chem. 276, 22077-22085. doi: 10.1074/jbc.M100774200

Hu, H., Wan, J., Huang, X., Tang, Y., Xiao, C., Xu, H., et al. (2018). iRGD-decorated reduction-responsive nanoclusters for targeted drug delivery. Nanoscale 10, 10514-10527. doi: 10.1039/c8nr02534g

Hu, Q., Sun, W., Wang, C., and Gu, Z. (2016). Recent advances of cocktail chemotherapy by combination drug delivery systems. Adv. Drug. Deliv. Rev. 98, 19-34. doi: 10.1016/j.addr.2015.10.022

Huang, G., and Huang, H. (2018). Hyaluronic acid-based biopharmaceutical delivery and tumor-targeted drug delivery system. J. Control Release 278, 122-126. doi: 10.1016/j.jconrel.2018.04.015

Hwang, T. J., Carpenter, D., Lauffenburger, J. C., Wang, B., Franklin, J. M., and Kesselheim, A. S. (2016). Failure of investigational drugs in late-stage clinical development and publication of trial results. JAMA Intern. Med. 176, 1826-1833. doi: 10.1001/jamainternmed.2016.6008 
Ishihara, J., Ishihara, A., Fukunaga, K., Sasaki, K., White, M. J. V., Briquez, P. S., et al. (2018). Laminin heparin-binding peptides bind to several growth factors and enhance diabetic wound healing. Nat. Commun. 9:2163. doi: 10.1038/ s41467-018-04525-w

Ishihara, J., Ishihara, A., Sasaki, K., Lee, S. S., Williford, J. M., Yasui, M., et al. (2019). Targeted antibody and cytokine cancer immunotherapies through collagen affinity. Sci. Transl. Med. 11:eaau3259. doi: 10.1126/scitranslmed.aau3259

Jeong, K. J., and Panitch, A. (2009). Interplay between covalent and physical interactions within environment sensitive hydrogels. Biomacromolecules 10 , 1090-1099. doi: 10.1021/bm801270k

Jiang, D., Liang, J., and Noble, P. W. (2011). Hyaluronan as an immune regulator in human diseases. Physiol. Rev. 91, 221-264. doi: 10.1152/physrev.00052.2009

Jiao, Y., Pang, X., and Zhai, G. (2016). Advances in hyaluronic acidbased drug delivery systems. Curr. Drug. Targets 17, 720-730. doi: 10. 217416666150531155200

Johnson, C. T., Wroe, J. A., Agarwal, R., Martin, K. E., Guldberg, R. E., Donlan, R. M., et al. (2018). Hydrogel delivery of lysostaphin eliminates orthopedic implant infection by Staphylococcus aureus and supports fracture healing. Proc. Natl. Acad. Sci. U.S.A. 115, E4960-E4969. doi: 10.1073/pnas.1801013115

Kanamala, M., Wilson, W. R., Yang, M., Palmer, B. D., and Wu, Z. (2016). Mechanisms and biomaterials in $\mathrm{pH}$-responsive tumour targeted drug delivery: a review. Biomaterials 85, 152-167. doi: 10.1016/j.biomaterials.2016.01.061

Kharkar, P. M., Kiick, K. L., and Kloxin, A. M. (2013). Designing degradable hydrogels for orthogonal control of cell microenvironments. Chem. Soc. Rev. 42, 7335-7372. doi: 10.1039/c3cs60040h

Kim, S. H., Turnbull, J., and Guimond, S. (2011). Extracellular matrix and cell signalling: the dynamic cooperation of integrin, proteoglycan and growth factor receptor. J. Endocrinol. 209, 139-151. doi: 10.1530/JOE-10-0377

Kim, Y. M., Park, S. C., and Jang, M. K. (2017). Targeted gene delivery of polyethyleneimine-grafted chitosan with RGD dendrimer peptide in alphavbeta3 integrin-overexpressing tumor cells. Carbohydr. Polym. 174, 10591068. doi: 10.1016/j.carbpol.2017.07.035

Kohane, D. S., and Todd, H. R. (2008). Hydrogels in drug delivery: progress and challenges. polymer 49, 1993-2007.

Kolmel, D. K., and Kool, E. T. (2017). Oximes and hydrazones in bioconjugation: mechanism and catalysis. Chem. Rev. 117, 10358-10376. doi: 10.1021/acs. chemrev.7b00090

Lallana, E., Rios, J., de la Rosa, M., Tirella, A., Pelliccia, M., Gennari, A., et al. (2017). Chitosan/hyaluronic acid nanoparticles: rational design revisited for RNA delivery. Mol. Pharm. 14, 2422-2436. doi: 10.1021/acs.molpharmaceut. $7 \mathrm{~b} 00320$

Langer, R. (1998). Drug delivery and targeting. Nature 392(6679 Suppl.), 5-10.

Leitinger, B. (2014). Discoidin domain receptor functions in physiological and pathological conditions. Int. Rev. Cell Mol. Biol. 310, 39-87. doi: 10.1016/B9780-12-800180-6.00002-5

Leitinger, B., and Hohenester, E. (2007). Mammalian collagen receptors. Matrix. Biol. 26, 146-155. doi: 10.1016/j.matbio.2006.10.007

Leonoudakis, D., Huang, G., Akhavan, A., Fata, J. E., Singh, M., Gray, J. W., et al. (2014). Endocytic trafficking of laminin is controlled by dystroglycan and is disrupted in cancers. J. Cell Sci. 127(Pt 22), 4894-4903. doi: 10.1242/jcs.152728

Li, J., and Mooney, D. J. (2016). Designing hydrogels for controlled drug delivery. Nat. Rev. Mater. 1, doi: 10.1038/natrevmats.2016.71

Liang, Y., and Kiick, K. L. (2014). Heparin-functionalized polymeric biomaterials in tissue engineering and drug delivery applications. Acta Biomater. 10, 15881600. doi: 10.1016/j.actbio.2013.07.031

Liu, D., Yang, F., Xiong, F., and Gu, N. (2016). The smart drug delivery system and its clinical potential. Theranostics 6, 1306-1323. doi: 10.7150/thno.14858

Lobert, V. H., Brech, A., Pedersen, N. M., Wesche, J., Oppelt, A., Malerod, L., et al. (2010). Ubiquitination of alpha 5 beta 1 integrin controls fibroblast migration through lysosomal degradation of fibronectin-integrin complexes. Dev. Cell 19, 148-159. doi: 10.1016/j.devcel.2010.06.010

Lohmann, N., Schirmer, L., Atallah, P., Wandel, E., Ferrer, R. A., Werner, C., et al. (2017). Glycosaminoglycan-based hydrogels capture inflammatory chemokines and rescue defective wound healing in mice. Sci. Transl. Med. 9:16071. doi: 10.1126/scitranslmed.aai9044

Lozeau, L. D., Grosha, J., Kole, D., Prifti, F., Dominko, T., Camesano, T. A., et al. (2017). Collagen tethering of synthetic human antimicrobial peptides cathelicidin LL37 and its effects on antimicrobial activity and cytotoxicity. Acta Biomater. 52, 9-20. doi: 10.1016/j.actbio.2016.12.047

Luo, T., David, M. A., Dunshee, L. C., Scott, R. A., Urello, M. A., Price, C., et al. (2017). Thermoresponsive Elastin-b-Collagen-Like peptide bioconjugate nanovesicles for targeted drug delivery to collagen-containing matrices. Biomacromolecules 18, 2539-2551. doi: 10.1021/acs.biomac.7b00686

Lutolf, M. P., Lauer-Fields, J. L., Schmoekel, H. G., Metters, A. T., Weber, F. E., Fields, G. B., et al. (2003). Synthetic matrix metalloproteinase-sensitive hydrogels for the conduction of tissue regeneration: engineering cell-invasion characteristics. Proc. Natl. Acad. Sci. U.S.A. 100, 5413-5418. doi: 10.1073/pnas. 0737381100

Madsen, D. H., Ingvarsen, S., Jurgensen, H. J., Melander, M. C., Kjoller, L., Moyer, A., et al. (2011). The non-phagocytic route of collagen uptake: a distinct degradation pathway. J. Biol. Chem. 286, 26996-27010. doi: 10.1074/jbc.M110. 208033

Mao, Z., Shi, H., Guo, R., Ma, L., Gao, C., Han, C., et al. (2009). Enhanced angiogenesis of porous collagen scaffolds by incorporation of TMC/DNA complexes encoding vascular endothelial growth factor. Acta Biomater. 5, 2983-2994. doi: 10.1016/j.actbio.2009.04.004

Massia, S. P., and Hubbell, J. A. (1992). Vascular endothelial cell adhesion and spreading promoted by the peptide REDV of the IIICS region of plasma fibronectin is mediated by integrin alpha 4 beta 1. J. Biol. Chem. 267, 1401914026.

Mateen, R., and Hoare, T. (2014). Injectable, in situ gelling, cyclodextrin-dextran hydrogels for the partitioning-driven release of hydrophobic drugs. Mater J. Chem. B 2, 5157-5167. doi: 10.1039/C4TB00631C

McBrien, N. A., Metlapally, R., Jobling, A. I., and Gentle, A. (2006). Expression of collagen-binding integrin receptors in the mammalian sclera and their regulation during the development of myopia. Invest. Ophthalmol. Vis. Sci. 47, 4674-4682. doi: 10.1167/iovs.05-1150

McKay, W. F., Peckham, S. M., and Badura, J. M. (2007). A comprehensive clinical review of recombinant human bone morphogenetic protein-2 (INFUSE Bone Graft). Int. Orthop. 31, 729-734. doi: 10.1007/s00264-007-0418-6

Meneghetti, M. C., Hughes, A. J., Rudd, T. R., Nader, H. B., Powell, A. K., Yates, E. A., et al. (2015). Heparan sulfate and heparin interactions with proteins. J. $R$. Soc. Interface 12:0589. doi: 10.1098/rsif.2015.0589

Merino, S., Martin, C., Kostarelos, K., Prato, M., and Vazquez, E. (2015). Nanocomposite hydrogels: 3D polymer-nanoparticle synergies for on-demand drug delivery. ACS Nano 9, 4686-4697. doi: 10.1021/acsnano.5b01433

Miyazaki, M., Yuba, E., Hayashi, H., Harada, A., and Kono, K. (2018). Hyaluronic acid-based pH-sensitive polymer-modified liposomes for cellspecific intracellular drug delivery systems. Bioconjug Chem. 29, 44-55. doi: 10.1021/acs.bioconjchem.7b00551

Morrison, C. (2018). Alnylam prepares to land first RNAi drug approval. Nat. Rev. Drug Discov. 17, 156-157. doi: 10.1038/nrd.2018.20

Mould, A. P., Komoriya, A., Yamada, K. M., and Humphries, M. J. (1991). The CS5 peptide is a second site in the IIICS region of fibronectin recognized by the integrin alpha 4 beta 1 . Inhibition of alpha 4 beta 1 function by RGD peptide homologues. J. Biol. Chem. 266, 3579-3585.

Munsell, E. V., Ross, N. L., and Sullivan, M. O. (2016). Journey to the Center Of The Cell: Current Nanocarrier Design Strategies Targeting Biopharmaceuticals To The Cytoplasm And Nucleus. Curr. Pharm. Des. 22, 1227-1244. doi: 10. 217422666151216151420

Murphy, E. A., Majeti, B. K., Barnes, L. A., Makale, M., Weis, S. M., and Lutu, K. (2008). Nanoparticle-mediated drug delivery to tumor vasculature suppresses metastasis. Proc. Natl. Acad. Sci. U.S.A. 105, 9343-9348. doi: 10.1073/pnas. 0803728105

Mythreye, K., and Blobe, G. C. (2009). Proteoglycan signaling co-receptors: roles in cell adhesion, migration and invasion. Cell Signal. 21, 1548-1558. doi: 10.1016/ j.cellsig.2009.05.001

Narayanaswamy, R., and Torchilin, V. P. (2019). Hydrogels and their applications in targeted drug delivery. Molecules 24:E603. doi: 10.3390/molecules 240 30603

Ndinguri, M. W., Zheleznyak, A., Lauer, J. L., Anderson, C. J., and Fields, G. B. (2012). Application of collagen-model triple-helical peptide-amphiphiles for CD44-TARGETED DRUG DELIVERY SYStems. J. Drug. Deliv. 2012:592602. doi: $10.1155 / 2012 / 592602$ 
Negishi, Y., Hamano, N., Omata, D., Fujisawa, A., Manandhar, M., Nomizu, M., et al. (2011). Effects of doxorubicin-encapsulating AG73 peptide-modified liposomes on tumor selectivity and cytotoxicity. Results Pharm. Sci. 1, 68-75. doi: 10.1016/j.rinphs.2011.10.001

Negishi, Y., and Nomizu, M. (2019). Laminin-derived peptides: applications in drug delivery systems for targeting. Pharmacol. Ther. 202, 91-97. doi: 10.1016/ j.pharmthera.2019.05.017

Negishi, Y., Omata, D., Iijima, H., Hamano, N., Endo-Takahashi, Y., Nomizu, M., et al. (2010). Preparation and characterization of laminin-derived peptide AG73-coated liposomes as a selective gene delivery tool. Biol. Pharm. Bull 33, 1766-1769. doi: 10.1248/bpb.33.1766

Nielsen, C. F., van Putten, S. M., Lund, I. K., Melander, M. C., Norregaard, K. S., Jurgensen, H. J., et al. (2017). The collagen receptor uPARAP/Endo180 as a novel target for antibody-drug conjugate mediated treatment of mesenchymal and leukemic cancers. Oncotarget 8, 44605-44624. doi: 10.18632/oncotarget. 17883

Nieto Gutierrez, A., and McDonald, P. H. (2018). GPCRs: emerging anti-cancer drug targets. Cell Signal. 41, 65-74. doi: 10.1016/j.cellsig.2017.09.005

Nikam, R. R., and Gore, K. R. (2018). Journey of siRNA: clinical developments and targeted delivery. Nucleic Acid Ther. 28, 209-224. doi: 10.1089/nat.2017.0715

Oh, E. J., Park, K., Kim, K. S., Kim, J., Yang, J. A., Kong, J. H., et al. (2010). Target specific and long-acting delivery of protein, peptide, and nucleotide therapeutics using hyaluronic acid derivatives. J. Control Release 141, 2-12. doi: 10.1016/j.jconrel.2009.09.010

Okur, A. C., Erkoc, P., and Kizilel, S. (2016). Targeting cancer cells via tumorhoming peptide CREKA functional PEG nanoparticles. Coll. Surf. B Biointerf 147, 191-200. doi: 10.1016/j.colsurfb.2016.08.005

Oliva, N., Conde, J., Wang, K., and Artzi, N. (2017). Designing hydrogels for on-demand therapy. Acc. Chem. Res. 50, 669-679. doi: 10.1021/acs.accounts. $6 \mathrm{~b} 00536$

Oliviero, O., Ventre, M., and Netti, P. A. (2012). Functional porous hydrogels to study angiogenesis under the effect of controlled release of vascular endothelial growth factor. Acta Biomater. 8, 3294-3301. doi: 10.1016/j.actbio.2012.05.019

Ooi, H. W., Hafeez, S., van, C. A., Blitterswijk, A., Moroni, L., et al. (2017). Hydrogels that listen to cells: a review of cell-responsive strategies in biomaterial design for tissue regeneration. Mater. Horizons 4, 1020-1040. doi: 10.1039/ c7mh00373k

Orsi, S., De, A., Capua, Guarnieri, D., Marasco, D., Netti, P. A., et al. (2010). Cell recruitment and transfection in gene activated collagen matrix. Biomaterials 31 , 570-576. doi: 10.1016/j.biomaterials.2009.09.054

Palmese, L. L., Thapa, R., Sullivan, M. O., and Kiick, K. L. (2019). Hybrid hydrogels for biomedical applications. Curr. Opin.Chem. Eng. 24, 143-157. doi: 10.1016/j. coche.2019.02.010

Pankov, R., and Yamada, K. M. (2002). Fibronectin at a glance. J. Cell Sci. 115(Pt 20), 3861-3863. doi: 10.1242/jcs.00059

Panyam, J., and Labhasetwar, V. (2003). Biodegradable nanoparticles for drug and gene delivery to cells and tissue. Adv. Drug Deliv. Rev. 55, 329-347.

Park, J. C., Hwang, Y. S., Lee, J. E., Park, K. D., Matsumura, K., Hyon, S. H., et al. (2000). Type I atelocollagen grafting onto ozone-treated polyurethane films: cell attachment, proliferation, and collagen synthesis. J. Biomed Mater. Res. 52, 669-677.

Park, J. W., Hwang, S. R., and Yoon, I. S. (2017). Advanced growth factor delivery systems in wound management and skin regeneration. Molecules 22:E1259. doi: 10.3390/molecules22081259

Pathak, A., Kumar, P., Chuttani, K., Jain, S., Mishra, A. K., Vyas, S. P., et al. (2009). Gene expression, biodistribution, and pharmacoscintigraphic evaluation of chondroitin sulfate-PEI nanoconstructs mediated tumor gene therapy. ACS Nano 3, 1493-1505. doi: 10.1021/nn900044f

Patterson, J., and Hubbell, J. A. (2010). Enhanced proteolytic degradation of molecularly engineered PEG hydrogels in response to MMP-1 and MMP-2. Biomaterials 31, 7836-7845. doi: 10.1016/j.biomaterials.2010.06.061

Phelps, E. A., Enemchukwu, N. O., Fiore, V. F., Sy, J. C., Murthy, N., Sulchek, T. A., et al. (2012). Maleimide cross-linked bioactive PEG hydrogel exhibits improved reaction kinetics and cross-linking for cell encapsulation and in situ delivery. Adv. Mater. 24, 64-70. doi: 10.1002/adma.201103574

Phuc, L. T. M., and Taniguchi, A. (2017). Epidermal growth factor enhances cellular uptake of polystyrene nanoparticles by clathrin-mediated endocytosis. Int. J. Mol. Sci. 18:1301. doi: 10.3390/ijms18061301
Prasad, V. (2014). The withdrawal of drugs for commercial reasons: the incomplete story of tositumomab. JAMA Intern. Med. 174, 1887-1888. doi: 10.1001/ jamainternmed.2014.5756

Prokoph, S., Chavakis, E., Levental, K. R., Zieris, A., Freudenberg, U., Dimmeler, S., et al. (2012). Sustained delivery of SDF-1alpha from heparin-based hydrogels to attract circulating pro-angiogenic cells. Biomaterials 33, 4792-4800. doi: 10.1016/j.biomaterials.2012.03.039

Qureshi, Z. P., Seoane-Vazquez, E., Rodriguez-Monguio, R., Stevenson, K. B., and Szeinbach, S. L. (2011). Market withdrawal of new molecular entities approved in the United States from 1980 to 2009. Pharmacoepidemiol. Drug Saf. 20, 772-777. doi: 10.1002/pds.2155

Raab-Westphal, S., Marshall, J. F., and Goodman, S. L. (2017). Integrins as therapeutic targets: successes and cancers. Cancers 9:E110. doi: 10.3390/ cancers 9090110

Raave, R., van Kuppevelt, T. H., and Daamen, W. F. (2018). Chemotherapeutic drug delivery by tumoral extracellular matrix targeting. J. Control Release 274, 1-8. doi: 10.1016/j.jconrel.2018.01.029

Racine, R., and Mummert, E. M. (2012). "Hyaluronan endocytosis: mechanisms of uptake and biological functions," in Molecular Regulation of Endocytosis, ed. B. Ceresa, (London: IntechOpen), 377-390.

Rainero, E. (2016). Extracellular matrix endocytosis in controlling matrix turnover and beyond: emerging roles in cancer. Biochem. Soc. Trans. 44, 1347-1354. doi: 10.1042/BST20160159

Raja, S. G. (2012). Local application of gentamicin-containing collagen implant in the prophylaxis and treatment of surgical site infection following cardiac surgery. Int. J. Surg. 10(Suppl. 1), S10-S14. doi: 10.1016/j.ijsu.2012.05.018

Ramshaw, J. A., Peng, Y. Y., Glattauer, V., and Werkmeister, J. A. (2009). Collagens as biomaterials. J. Mater. Sci. Mater. Med. 20(Suppl. 1), S3-S8. doi: 10.1007/ s10856-008-3415-4

Reilly, M. J., Larsen, J. D., and Sullivan, M. O. (2012). Polyplexes traffic through caveolae to the Golgi and endoplasmic reticulum en route to the nucleus. Mol. Pharm. 9, 1280-1290. doi: 10.1021/mp200583d

Rejman, J., Bragonzi, A., and Conese, M. (2005). Role of clathrin- and caveolaemediated endocytosis in gene transfer mediated by lipo- and polyplexes. Mol . Ther. 12, 468-474. doi: 10.1016/j.ymthe.2005.03.038

Rezler, E. M., Khan, D. R., Lauer-Fields, J., Cudic, M., Baronas-Lowell, D., et al. (2007). Targeted drug delivery utilizing protein-like molecular architecture. J. Am. Chem. Soc. 129. doi: 10.1021/ja066929m

Roggenbuck, D., Mytilinaiou, M. G., Lapin, S. V., Reinhold, D., and Conrad, K. (2012). Asialoglycoprotein receptor (ASGPR): a peculiar target of liver-specific autoimmunity. Auto Immun. Highlights 3, 119-125. doi: 10.1007/s13317-0120041-4

Rosso, F., Giordano, A., Barbarisi, M., and Barbarisi, A. (2004). From cell-ECM interactions to tissue engineering. J. Cell Physiol. 199, 174-180. doi: 10.1002/ jcp. 10471

Ruoslahti, E. (2002). Drug targeting to specific vascular sites. Drug Discov. Today 7, 1138-1143.

Ruoslahti, E., and Pierschbacher, M. D. (1986). Arg-Gly-Asp: a versatile cell recognition signal. Cell 44, 517-518. doi: 10.1016/0092-8674(86)90259-x

Ruskowitz, R. E., and DeForest, A. C. (2018). Photoresponsive biomaterials for targeted drug delivery and 4D cell culture. Nat. Rev. Mater. 3, 1-17. doi: 10. 1038/natrevmats2017.87

Sahay, G., Alakhova, D. Y., and Kabanov, A. V. (2010). Endocytosis of nanomedicines. J. Control Release 145, 182-195. doi: 10.1016/j.jconrel.2010. 01.036

Sakiyama-Elbert, S. E., and Hubbell, J. A. (2000). Development of fibrin derivatives for controlled release of heparin-binding growth factors. J. Control Release 65, 389-402. doi: 10.1016/s0168-3659(99)00221-7

Saldin, L. T., Cramer, M. C., Velankar, S. S., White, L. J., and Badylak, S. F. (2017). Extracellular matrix hydrogels from decellularized tissues: Structure and function. Acta Biomater. 49, 1-15. doi: 10.1016/j.actbio.2016.11.068

Sato, K., Hendricks, M. P., Palmer, L. C., and Stupp, S. I. (2018). Peptide supramolecular materials for therapeutics. Chem. Soc. Rev. 47, 7539-7551. doi: $10.1039 / \mathrm{c} 7 \mathrm{cs} 00735 \mathrm{c}$

Schiffelers, R. M., Ansari, A., Xu, J., Zhou, Q., Tang, Q., Storm, G., et al., (2004). Cancer siRNA therapy by tumor selective delivery with ligand-targeted sterically stabilized nanoparticle. Nucleic Acids Res. 32:e149. doi: 10.1093/nar/ gnh140 
Schnittert, J., Bansal, R., Storm, G., and Prakash, J. (2018). Integrins in wound healing, fibrosis and tumor stroma: high potential targets for therapeutics and drug delivery. Adv. Drug Deliv. Rev. 129, 37-53. doi: 10.1016/j.addr.2018.01.020

Seif-Naraghi, S. B., Horn, D., Schup-Magoffin, P. J., and Christman, K. L. (2012). Injectable extracellular matrix derived hydrogel provides a platform for enhanced retention and delivery of a heparin-binding growth factor. Acta Biomater. 8, 3695-3703. doi: 10.1016/j.actbio.2012.06.030

She, W., Li, N., Luo, K., Guo, C., Wang, G., Geng, Y., et al. (2013). Dendronized heparin-doxorubicin conjugate based nanoparticle as $\mathrm{pH}$-responsive drug delivery system for cancer therapy. Biomaterials 34, 2252-2264. doi: 10.1016/ j.biomaterials.2012.12.017

Sheikhpour, M., Barani, L., and Kasaeian, A. (2017). Biomimetics in drug delivery systems: a critical review. J. Control Release 253, 97-109. doi: 10.1016/j.jconrel. 2017.03.026

Shekaran, A., Garcia, J. R., Clark, A. Y., Kavanaugh, T. E., Lin, A. S., Guldberg, R. E., et al. (2014). Bone regeneration using an alpha 2 beta 1 integrin-specific hydrogel as a BMP-2 delivery vehicle. Biomaterials 35, 5453-5461. doi: 10.1016/ j.biomaterials.2014.03.055

Shi, F., and Sottile, J. (2008). Caveolin-1-dependent betal integrin endocytosis is a critical regulator of fibronectin turnover. J. Cell Sci. 121(Pt 14), 2360-2371. doi: $10.1242 /$ jcs.014977

Shing, Y., Folkman, J., Sullivan, R., Butterfield, C., Murray, J., Klagsbrun, M., et al. (1984). Heparin affinity: purification of a tumor-derived capillary endothelial cell growth factor. Science 223, 1296-1299. doi: 10.1126/science.6199844

Shukla, R., Chanda, N., Zambre, A., Upendran, A., Katti, K., Kulkarni, R. R., et al. (2012). Laminin receptor specific therapeutic gold nanoparticles (198AuNPEGCg) show efficacy in treating prostate cancer. Proc. Natl. Acad. Sci. U.S.A. 109, 12426-12431. doi: 10.1073/pnas.1121174109

Silva, G. A., Czeisler, C., Niece, K. L., Beniash, E., Harrington, D. A., Kessler, J. A., et al. (2004). Selective differentiation of neural progenitor cells by high-epitope density nanofibers. Science 303, 1352-1355. doi: 10.1126/science.1093783

Sood, N., Bhardwaj, A., Mehta, S., and Mehta, A. (2016). Stimuli-responsive hydrogels in drug delivery and tissue engineering. Drug Deliv. 23, 758-780. doi: 10.3109.2014.940091

Storrie, H., Guler, M. O., Abu-Amara, S. N., Volberg, T., Rao, M., Geiger, B., et al. (2007). Supramolecular crafting of cell adhesion. Biomaterials 28, 4608-4618. doi: 10.1016/j.biomaterials.2007.06.026

Tanihara, M., Suzuki, Y., Yamamoto, E., Noguchi, A., Mizushima, Y., et al. (2001). Sustained release of basic fibroblast growth factor and angiogenesis in a novel covalently crosslinked gel of heparin and alginate. J. Biomed Mater. Res. 56, 216-221.

Tashiro, K., Sephel, G. C., Weeks, B., Sasaki, M., Martin, G. R., Kleinman, H. K., et al. (1989). A synthetic peptide containing the IKVAV sequence from the A chain of laminin mediates cell attachment, migration, and neurite outgrowth. J. Biol. Chem. 264, 16174-16182.

Theocharis, A. D., Skandalis, S. S., Gialeli, C., and Karamanos, N. K. (2016). Extracellular matrix structure. Adv. Drug Deliv. Rev. 97, 4-27. doi: 10.1016/j. addr.2015.11.001

Tibbitt, M. W., Dahlman, J. E., and Langer, R. (2016). Emerging frontiers in drug delivery. J. Am. Chem. Soc. 138, 704-717. doi: 10.1021/jacs.5b09974

Torchilin, V. P. (2014). Multifunctional, stimuli-sensitive nanoparticulate systems for drug delivery. Nat. Rev. Drug Discov. 13, 813-827. doi: 10.1038/nrd4333

Tripodo, G., Trapani, A., Torre, M. L., Giammona, G., Trapani, G., and Mandracchia, D. (2015). Hyaluronic acid and its derivatives in drug delivery and imaging: recent advances and challenges. Eur. J. Pharm. Biopharm. 97(Pt B), 400-416. doi: 10.1016/j.ejpb.2015.03.032

Truong, N. F., Lesher-Perez, S. C., Kurt, E., and Segura, T. (2019). Pathways governing polyethylenimine polyplex transfection in microporous annealed particle scaffolds. Bioconjug Chem. 30, 476-486. doi: 10.1021/acs.bioconjchem. 8 b00696

Truong, N. F., and Segura, T. (2018). Sustained transgene expression via hydrogelmediated gene transfer results from multiple transfection events. ACS Biomater. Sci. Eng 4, 981-987. doi: ..1021/acsbiomaterials.7b00957

Tsuji, T., Yoshitomi, H., and Usukura, J. (2013). Endocytic mechanism of transferrin-conjugated nanoparticles and the effects of their size and ligand number on the efficiency of drug delivery. Microscopy 62, 341-352. doi: 10.1093/ jmicro/dfs080

Tsurkan, M. V., Hauser, P. V., Zieris, A., Carvalhosa, R., Bussolati, B., Freudenberg, U., et al. (2013). Growth factor delivery from hydrogel particle aggregates to promote tubular regeneration after acute kidney injury. J. Control Release 2013, 248-255. doi: 10.1016/j.jconrel.2013.01.030

Ulrich, S., Boturyn, D., Marra, A., Renaudet, O., and Dumy, P. (2014). Oxime ligation: a chemoselective click-type reaction for accessing multifunctional biomolecular constructs. Chemistry 20, 34-41. doi: 10.1002/chem.20130 2426

Urello, M. A., Kiick, K. L., and Sullivan, M. O. (2016). Integration of growth factor gene delivery with collagen-triggered wound repair cascades using collagen-mimetic peptides. Bioeng Transl. Med. 1, 207-219. doi: 10.1002/btm2.1 0037

Urello, M. A., Kiick, K. L., and Sullivan, M. O. (2017). ECM turnoverstimulated gene delivery through collagen-mimetic peptide-plasmid integration in collagen. Acta Biomater. 62, 167-178. doi: 10.1016/j.actbio.2017.08.038

Urello, M. A., Kiick, K. L., and Sullivan, M. O. (2014). A CMP-based method for tunable, cell-mediated gene delivery from collagen scaffolds. Mater. J. Chem. B 8174-8185. doi: 10.1039/c4tb01435a

Wang, C., and Gao, C. (2014). Design of gene-activated matrix for the repair skin and cartilage. Polym. J. 46, 476-482. doi: 10.1038/pj.2014.50

Wang, H., Feng, Y., Yang, J., Guo, J., and Zhang, W. (2015). Targeting REDV peptide functionalized polycationic gene carrier for enhancing the transfection and migration capability of human endothelial cells. J. Mater. Chem. B 3, 3379-3391. doi: 10.1039/C4TB02019G

Wang, Y. (2018). Programmable hydrogels. Biomaterials 178, 663-680. doi: 10. 1016/j.biomaterials.2018.03.008

Webber, M. J., Tongers, J., Renault, M. A., Roncalli, J. G., Losordo, D. W., et al. (2010). Development of bioactive peptide amphiphiles for therapeutic cell delivery. Acta Biomater 6, 3-11. doi: 10.1016/j.actbio.2009.07.031

Wojtowicz, A. M., Shekaran, A., Oest, M. E., Dupont, K. M., Templeman, K. L., Hutmacher, D. W., et al. (2010). Coating of biomaterial scaffolds with the collagen-mimetic peptide GFOGER for bone defect repair. Biomaterials 31, 2574-2582. doi: 10.1016/j.biomaterials.2009.12.008

Xu, S., Olenyuk, B. Z., Okamoto, C. T., and Hamm-Alvarez, S. F. (2013). Targeting receptor-mediated endocytotic pathways with nanoparticles: rationale and advances. Adv. Drug Deliv Rev. 65, 121-138. doi: 10.1016/j.addr.2012. 09.041

Yameen, B., Choi, W. I., Vilos, C., Swami, A., Shi, J., and Farokhzad, O. C. (2014). Insight into nanoparticle cellular uptake and intracellular targeting. J. Control Release 190, 485-499. doi: 10.1016/j.jconrel.2014.06.038

Yao, Y. (2017). Laminin: loss-of-function studies. Cell Mol. Life Sci. 74, 1095-1115. doi: 10.1007/s00018-016-2381-0

Yigit, S., Sanyal, R., and Sanyal, A. (2011). Fabrication and functionalization of hydrogels through click chemistry. Chem. Asian. J. 6, 2648-2659. doi: 10.1002/ asia. 201100440

Yoneda, A., and Couchman, J. R. (2003). Regulation of cytoskeletal organization by syndecan transmembrane proteoglycans. Matrix Biol. 22, 25-33.

Zeltz, C., Orgel, J., and Gullberg, D. (2014). Molecular composition and function of integrin-based collagen glues-introducing COLINBRIs. Biochim. Biophys. Acta 1840, 2533-2548. doi: 10.1016/j.bbagen.2013.12.022

Zhang, Y. S., and Khademhosseini, A. (2017). Advances in engineering hydrogels. Science 356:eaaf3627. doi: 10.1126/science.aaf3627

Zhao, L., Liu, M., Wang, J., and Zhai, G. (2015). Chondroitin sulfate-based nanocarriers for drug/gene delivery. Carbohydr. Polym. 133, 391-399. doi: 10. 1016/j.carbpol.2015.07.063

Zhong, H., Chan, G., Hu, Y., Hu, H., and Ouyang, D. (2018). A comprehensive map of FDA-approved pharmaceutical products. Pharmaceutics 10:E263. doi: 10.3390/pharmaceutics10040263

Zhou, F., Jia, X., Yang, Q., Yang, Y., Zhao, Y., Fan, Y., et al. (2016). Targeted delivery of microRNA-126 to vascular endothelial cells via REDV peptide modified PEG-trimethyl chitosan. Biomater. Sci. 4, 849-856. doi: 10.1039/c5bm00 $629 \mathrm{e}$

Zhou, S., Hokugo, A., McClendon, M., Zhang, Z., Bakshi, R., and Wang, L. (2019). Bioactive peptide amphiphile nanofiber gels enhance burn wound healing. Burns 45, 1112-1121. doi: 10.1016/j.burns.2018.06.008

Zieris, A., Chwalek, K., Prokoph, S., Levental, K. R., Welzel, P. B., Freudenberg, U., et al. (2011). Dual independent delivery of pro-angiogenic growth factors from starPEG-heparin hydrogels. J. Control Release 156, 28-36. doi: 10.1016/j. jconrel.2011.06.042

Zieris, A., Prokoph, S., Levental, K. R., Welzel, P. B., Grimmer, M., Freudenberg, U., et al. (2010). FGF-2 and VEGF functionalization of starPEG-heparin hydrogels 
to modulate biomolecular and physical cues of angiogenesis. Biomaterials 31, 7985-7994. doi: 10.1016/j.biomaterials.2010.07.021

Zilberman, M., and Elsner, J. J. (2008). Antibiotic-eluting medical devices for various applications. J. Control Release 130, 202-215. doi: 10.1016/j.jconrel. 2008.05.020

Zollinger, A. J., and Smith, M. L. (2017). Fibronectin, the extracellular glue. Matrix Biol. 6, 27-37. doi: 10.1016/j.matbio.2016.07.011

Zustiak, S. P., and Leach, J. B. (2010). Hydrolytically degradable poly(ethylene glycol) hydrogel scaffolds with tunable degradation and mechanical properties. Biomacromolecules 11, 1348-1357. doi: 10.1021/bm100137q
Conflict of Interest: The authors declare that the research was conducted in the absence of any commercial or financial relationships that could be construed as a potential conflict of interest.

Copyright (c) 2020 Hwang, Sullivan and Kiick. This is an open-access article distributed under the terms of the Creative Commons Attribution License (CC BY). The use, distribution or reproduction in other forums is permitted, provided the original author(s) and the copyright owner(s) are credited and that the original publication in this journal is cited, in accordance with accepted academic practice. No use, distribution or reproduction is permitted which does not comply with these terms. 